\title{
Hepatic gene expression in flounder chronically exposed to multiply- polluted estuarine sediment: Absence of classical exposure 'biomarker' signals and induction of inflammatory, innate immune and apoptotic pathways.
}

Michael J. Leaver ${ }^{*}$, Amer Diab ${ }^{1}$, Evridiki Boukouvala ${ }^{4 \$}$, Tim D. Williams ${ }^{2}$, J. Kevin Chipman $^{2}$, Colin F. Moffat ${ }^{3}$, Craig D. Robinson ${ }^{3}$, Stephen G. George ${ }^{1}$

1. Institute of Aquaculture, University of Stirling, Stirling FK9 4LA, UK

2. School of Biosciences, University of Birmingham, Birmingham B15 2TT, UK

3. Marine Scotland, Marine Laboratory, 375 Victoria Road, Aberdeen AB11 9DB, UK

*. Corresponding author: email; mj11@stir.ac.uk, Tel: +44 (0)1786467995, Fax; +44 (0) 1786472133

\$. Permanent address: National Agricultural Research Foundation, Fisheries Research Institute, Kavala 64007, Greece

\begin{abstract}
The effects of chronic long term exposure to multiply-polluted environments on fish are not well understood, but environmental surveys suggest that such exposure may cause a variety of pathologies, including cancers. Transcriptomic profiling has recently been used to assess gene expression in European flounder (Platichthys flesus) living in several polluted and clean estuaries. However, the gene expression changes detected were not unequivocally elicited by pollution, most likely due to the confounding effects of natural estuarine ecosystem variables. In this study flounder from an uncontaminated estuary were held on clean or polluted sediments in mesocosms, allowing control of variables such as salinity, temperature, and diet. After 7 months flounder were removed from each mesocosm and hepatocytes prepared from fish exposed to clean or polluted sediments. The hepatocytes were treated with benzo(a)pyrene (BAP), estradiol (E2), copper, a mixture of these three, or with the vehicle DMSO. A flounder cDNA microarray was then used to measure hepatocyte transcript abundance after each treatment. The results show that long term chronic exposure to a multiply-polluted sediment causes increases in the expression of mRNAs coding for proteins of the endogenous apoptotic program, of innate immunity and inflammation. Contrary to expectation, the expression of mRNAs which are commonly used as biomarkers of environmental exposure to particular contaminants were not changed, or were changed contrary to expectation. However, acute treatment of hepatocytes from flounder from both clean and polluted sediments with BAP or E2 caused the expected changes in the expression of these biomarkers. Thus transcriptomic analysis of flounder exposed long-term to chronic pollution causes a different pattern of gene expression than in fish acutely treated with single chemicals, and reveals novel potential biomarkers of environmental contaminant exposure. These novel biomarkers include Diablo, a gene involved in apoptotic pathways and highly differentially regulated by both chronic and acute exposure to multiple pollutants.
\end{abstract}

\section{Introduction}

Estuarine sediments are sinks for chemical pollutants present in industrial and domestic effluents, and the health of fish which live in polluted estuaries is of concern. The European flounder lives in close association with estuarine sediments and is a key sentinel species for biological effects monitoring in initiatives such as the OSPAR Joint Assessment 
and Monitoring Programme (OSPAR, 2003). Such biological effects monitoring programmes have concentrated on the use of biochemical, molecular, histopathological and morphological biomarkers to indicate exposure to harmful pollutants (van der Oost et al., 2003). The development of these biomarkers has most often been based on identifying endpoints which vary after single acute experimental exposure to model pollutants, such as polycyclic aromatic hydrocarbons (PAH), halogenated aromatic hydrocarbons, estrogenic chemicals, and metals. However, changes in these markers are not always observed in field surveys, even in fish exposed to high levels of contaminants (Eggens et al., 1996) (Reynolds et al., 2003).

The development of transcriptomic techniques for massively parallel, simultaneous measurement of expression of several thousands of genes may provide a means to assess, not only exposure but also mechanisms of action and effects of environmental contaminants. Transcriptomic profiling with targeted microarrays has been used to assess the effects of exposure to polluted sediments and in some of these studies it has been possible to obtain a toxicologically relevant signal from amongst the transcripts which were changed. Thus, when comparing a highly PAH-contaminated environment with a 'clean' reference site, flounder transcripts characteristic of acute PAH-response were changed (Williams et al., 2003). Similarly, when comparing hornyhead turbot (Pleuronichthys verticalis) from a site receiving an estrogenic effluent with a clean site, a signal characteristic of acute estrogen exposure was observed (Baker et al., 2009). However, in a larger study, involving several European estuaries of differing pollutant status, and using a more comprehensive microarray, a transcriptomic signal of pollutant effect was less clear (Falciani et al., 2008). These results demonstrated that gene expression profiles depended on site, and that the relative expression levels of a subset of 17 genes could predict the source of flounder with high accuracy. However, this subset only contained one currently described biomarker, CYP1A, and furthermore transcriptomic profiling of flounder experimentally exposed to acute doses of model pollutants (Williams et al., 2008) showed large differences to gene expression profiles in fish from polluted environments. These results have general similarities to studies on populations of Fundulus heteroclitus, a fish which inhabits severely contaminated estuarine sites in North America. Comparing gene expression profiles of $F$. heteroclitus from several polluted and unpolluted sites indicates that in each of the polluted populations 5 to $17 \%$ of genes are differentially expressed, yet only two genes had a consistent difference in expression among all polluted sites (Fisher and Oleksiak, 2007). Also notable was an apparent under-representation of the type of biomarker genes which might have been expected to be differentially expressed between polluted and unpolluted sites, although in the case of $F$. heteroclitus there appears to be a heritable resistance to the effects of some contaminants, which is believed to prevent CYP1A induction for example (Oleksiak, 2008).

It is perhaps not surprising that comparing gene expression in different populations of fish from different locations is not straightforward. Estuaries in particular are highly variable environments and it is possible that pollutant responses are masked by large changes in expression of other genes that may be responsive to variables such as salinity, temperature, feeding, and, as shown with $F$. heteroclitus, population differences. It is also possible that the long-term response to living on multiply-polluted sediments differs from the response to acute, short-term, single-chemical exposures which have been used to identify many of the current commonly used molecular and biochemical biomarkers. The aim of the study reported here was to compare the transcriptomic effects of chronic exposure to a real polluted estuarine sediment with a real 'clean' sediment in a single population of flounder. This was achieved by chronic exposure in a controlled mesocosm study designed to eliminate many of the variables present in different estuaries, followed by microarray and quantitative PCR measurement of gene expression in isolated hepatocytes from exposed and 
unexposed fish. The use of isolated hepatocytes provided a means to directly compare the transcriptomic effects of acute exposure to prototypical pollutants with long-term chronic exposure to sediments, whilst minimizing the effects of natural genetic and environmental variation in outbred wild populations of fish.

\section{Methods}

\subsection{Experimental animals}

Juvenile (0-group) flounder, were collected by beam trawl at low tide in May-June from the Ythan estuary (NE Scotland). Benthic invertebrates (mostly Tellina and Macoma bivalves, together with some polychaete worms) were collected by wet sieving (4 $\mathrm{mm})$ from clean sediment at the Ythan estuary, Loch Ewe (NW Scotland), and at Balmerino on the Firth of Tay estuary (E Scotland).

\subsection{Mesocosm Establishment}

The mesocosms consisted of four $1.5 \mathrm{~m}$ tanks contained $4-5 \mathrm{~cm}$ of test sediment over $\sim 3 \mathrm{~cm}$ of filter sand, covering $\sim 5 \mathrm{~cm}$ of filter gravel, on top of perforated, corrugated plastic sitting on the base of the tank. Four air-riser pipes per tank ensured a circulation of water down through the sediment and up the air-riser in order to prevent anoxia of the sediment, reduce sediment resuspension, and lessen water turbidity. Each mesocosm was supplied with $\sim 100 \mathrm{~L}$ per hour of carbon-filtered $50 \%$ seawater $\left(\right.$ salinity $=17 \mathrm{gL}^{-1}$ ).

Three bulk sediments were collected for use in the mesocosm experiments. Two contaminated sediments were obtained from dredged material from the estuary of the River Tyne, Riverside Quay, Jarrow, and also sediment collected by van Veen grab from the Firth of Forth, adjacent to the Grangemouth petrochemical complex. A clean reference sediment was manually collected from the estuary of the River Ythan, in North East Scotland, adjacent to the site of flounder collection. Each of the sediments was thoroughly mixed, and stored as large $(\sim 75 \mathrm{~kg})$ aliquots that were held in plastic packing crates within a commercial frozen storage facility until required.

Prior to introducing flounder to the tanks, the bulk Forth and Tyne sediments were combined (FT). This sediment and the reference Ythan (Y) sediment were each thoroughly mixed (75:25) with filter sand, and aliquoted/stored as described above. The filter sand was added to equalize the grain size of all sediments and to reduce the likelihood of the sediment becoming anoxic during the test. The final test sediments, ie mixed and with filter sand added, are hereafter referred to as 'clean' and 'polluted'.

The test sediments were added to duplicate tanks in May and benthic invertebrates were added 30 days later. After a further 30 days 600 -group flounder $(3.1 \pm 1.1 \mathrm{~g}, 56 \pm 6 \mathrm{~mm})$ were added to each tank. Benthic in situ invertebrate prey species were supplemented daily with frozen mysid shrimp (at a rate of $\sim 1 \%$ of body weight/day) and once a week with commercial pellets (Bio-Optimal START 1.5mm, Biomar, 1\% of body weight/week). Water temperature and salinity were recorded weekly. After three months, an additional $1-2 \mathrm{~cm}$ of test sediment was added to each mesocosm and the mesocosm-exposed fish were sampled after 7 months of exposure to the sediments.

Five aliquots from each of the 'clean' and polluted' sediments were collected for chemical analysis at the point of first addition to the tanks.

Tanks were regularly inspected for mortalities and dead fish removed. After 7 months, surviving fish were counted and taken for biometric, chemical and biological analyses. Salinity over the course of the experiment was $19.8 \pm 1.5 \%$ (mean of weekly measurements from each of the 4 tanks) and temperature was $12.3 \pm 2.7^{\circ} \mathrm{C}$ (mean of weekly 
measurements from each of the 4 tanks), ranging from a maximum of $16^{\circ} \mathrm{C}$ to a minimum of $8^{\circ} \mathrm{C}$, in accordance with the normal environmental variation over the period.

\subsection{Sediment chemistry}

Unless stated otherwise, chemical analyses were accredited to ISO/IEC 17025:2005 by the UK Accreditation Service.

\subsubsection{Determination of sediment characteristics}

The particle size distributions of freeze dried test sediments were determined using a laser granulometer, after initial sieving to $2 \mathrm{~mm}$. The concentrations of Total, Inorganic, and Organic Carbon (TC, TIC, TOC) in freeze dried sediments, were determined using an elemental analyser. Finely ground sediment samples were analysed either without acidification (TC), or following the addition of hydrochloric acid (TOC). TIC was determined as the difference between the two.

\subsubsection{Determination of trace metal concentrations}

Freeze dried samples of test sediment were sieved $(2 \mathrm{~mm})$ and the fine material ballmilled before being digested in a closed vessel microwave using concentrated nitric acid. Fish samples were homogenised and similarly digested. Sample digests were diluted, internal standards added, and trace element concentrations determined by Inductively Coupled Plasma Mass Spectrometry (ICPMS). Concentrations of $\mathrm{Cr}, \mathrm{Ni}, \mathrm{Cu}, \mathrm{Zn}, \mathrm{As}, \mathrm{Cd}$, $\mathrm{Hg}$, and $\mathrm{Pb}$ were determined in sediments and flounder muscle and liver; additionally $\mathrm{Mn}$, $\mathrm{Co}$ and Se were also determined in flounder muscle and liver.

\subsubsection{Determination of polycyclic aromatic hydrocarbons (PAHs)}

Hydrocarbons, including PAHs, were extracted from wet test sediment by sonication in dichloromethane and methanol, and from flounder muscle and liver by saponification. The extracts were purified and the PAHs separated from the aliphatic hydrocarbons using high performance liquid chromatography (HPLC). Quantitative analysis of 40 two- to sixring (parent and branched) PAHs was carried out by gas chromatography with mass selective detection (GC-MSD, (Webster et al., 2009) (Webster et al., 2004). Results are presented as total naphthalenes (naphthalene +1 -methyl naphthalene +2 -methyl naphthalene $+\mathrm{C} 2, \mathrm{C} 3, \mathrm{C} 4$ naphthalenes), total of the $40 \mathrm{PAH}$ compounds, or as total benzo[a]pyrene-equivalent PAH concentrations (derived from the function of individual compound concentration and the Toxic Equivalency Factor (TEF), for the 16 PAH compounds for which TEFs are available.

\subsubsection{Determination of chlorinated biphenyls (CBs) and organochlorine pesticides (OCPs)}

$\mathrm{CBs}$ and OCPs were extracted from freeze dried sediments and dehydrated samples by either soxhlet extraction using methyl-tert-butyl ether (MTBE) as the solvent or by Pressurised Liquid Extraction (PLE) using iso-hexane and with 5\% deactivated alumina in the PLE cells as a fat retainer to partially clean-up the samples. Concentrated extracts were further cleaned-up and OCPs and CBs separated with deactivated silica and the concentrations of $28 \mathrm{CB}$ congeners and 20 OCPs determined by gas chromatography with electron capture detection (GC-ECD; (Webster et al., 2009)). The determined OCPs were o,p' DDE, p,p' DDE, o,p' DDD, p,p' DDD, o,p' DDT, p,p' DDT, $\alpha$-chlordene, $\gamma$-chlordene, oxychlordane, $\alpha$-chlordane, $\gamma$-chlordane, total heptachlor, heptachlor epoxide, transnonachlor, dieldrin, aldrin, endrin, $\alpha-\mathrm{HCH}, \gamma-\mathrm{HCH}$, and hexachlorobenzene (HCB). Concentrations of individual CBs were determined and the reported results also included the total concentration of all the CBs monitored and the total of the "ICES7" CBs (sum of CBs 
$28,52,101,118,138,153$ and 180). Individual OCP concentrations were often below detection limits; data for those compounds most-often detected are presented (the sum of DDT and its metabolites, HCB) together with the sum of all OCP compounds.

\subsubsection{Determination of organotin compounds}

Freeze dried test sediment samples were sieved $(2 \mathrm{~mm})$ and the fine material ballmilled before organotin compounds were extracted using acetic acid and methanol. Extracted organotins were derivatised using sodium tetraethylborate and the ethylated organotins simultaneously re-extracted into iso-hexane. The iso-hexane extracts were cleaned-up with deactivated silica and the concentrations of ethylated di-, and tri-butyltin were determined by GC-MSD.

\subsubsection{Determination of polybrominated diphenylethers (PBDEs)}

PBDEs were extracted from freeze dried test sediments and dehydrated samples by PLE using iso-hexane as solvent. The concentrated extracts were cleaned-up and the concentrations of 17 (tri- to deca-brominated) PBDE congeners determined by GC-MSD (Webster et al., 2009).

\subsection{Hepatocyte preparation and treatment}

The overall experimental scheme is shown in Figure 1. Four male fish and two female flounder from each test group ('clean' and 'polluted') were selected randomly, by netting all fish into a holding tank and sampling the first four males and two females to be sub-sampled. These fish had lengths between 12 and $16.3 \mathrm{~cm}$. The skin of the fish was swabbed with $10 \%$ FAM disinfectant before removing livers. A sub-sample of each liver was frozen in liquid $\mathrm{N}_{2}$ for individual analyses. The remainder of each liver was finely chopped and hepatocytes prepared as described previously (Leaver et al., 2007). Following hepatocyte preparation washed cell pellets were resuspended in $10 \mathrm{ml}$ of DMEM, $10 \% \mathrm{FBS}$, PSK and cell concentration determined in each preparation using a hemocytometer. Two pools were then made containing equal numbers of cells originating from each of the six flounder from each 'clean' or 'polluted' group. These pools were then distributed to six-well polystyrene culture

dishes to provide $10^{6}$ cells in $2 \mathrm{ml}$ in each well. Culture dishes were incubated for 2 hours at $12^{\circ} \mathrm{C}, 4 \% \mathrm{CO}_{2}$ before adding $5 \mu 1$ of DMSO or $5 \mu 1$ DMSO containing $20 \mathrm{mM}$ benzo(a)pyrene (BAP), $0.4 \mathrm{mM}$ estradiol (E2) or $4 \mathrm{mM}$ copper sulphate $(\mathrm{Cu})$, to give final exposure concentrations of $50 \mu \mathrm{M}$ BAP, $1 \mu \mathrm{M}$ E2 and $10 \mu \mathrm{M} \mathrm{Cu}$. Hepatocytes were also treated with a mixture of all three compounds (MIX), each at the concentrations stated above. All treatments were performed as six replicates. After 40 hours of exposure at $12^{\circ} \mathrm{C}, 4 \% \mathrm{CO}_{2}$, three replicates of each treatment were harvested by aspiration and cells pelleted at $1000 \mathrm{~g}$ for 3 mins. Cell pellets were immediately resuspended with vigorous vortex mixing in $200 \mu 1$ of RNA extraction solution (TriReagent, Sigma). Cells in the remaining culture dish wells were assessed for viability by counting number of cells excluding Trypan Blue using a hemocytometer and microscope. Viability was between 72 and $81 \%$ in all treatments after 40 hours and did not significantly vary between treatments.

\subsection{Microarray Hybridisation}

Total RNA was prepared from pooled hepatocyte cell pellets using TriReagent RNA extraction buffer (Sigma) according to the manufacturers protocol. Each hepatocyte 
treatment consisted of three experimental replicates for microarray hybridisation. Total RNA from individual livers was prepared by homogenising liver fragments in $8 \mathrm{ml} / \mathrm{g}$ methanol, $2.5 \mathrm{ml} / \mathrm{g}$ water. One hundred microlitres of the aqueous phase was then processed for RNA purification using binding to/elution from an anion exchange mini-column (RNeasy Midi Kit, Qiagen). Final RNA concentrations were measured using a Nanodrop spectrophotometer and integrity checked by assessing the relative proportions of $28 \mathrm{~S}$ and 18S RNA using agarose gel electrophoresis. All samples showed approximately 2 fold more ethidium bromide staining in $28 \mathrm{~S}$ band than in $18 \mathrm{~S}$ band, indicating that the samples were not significantly degraded.

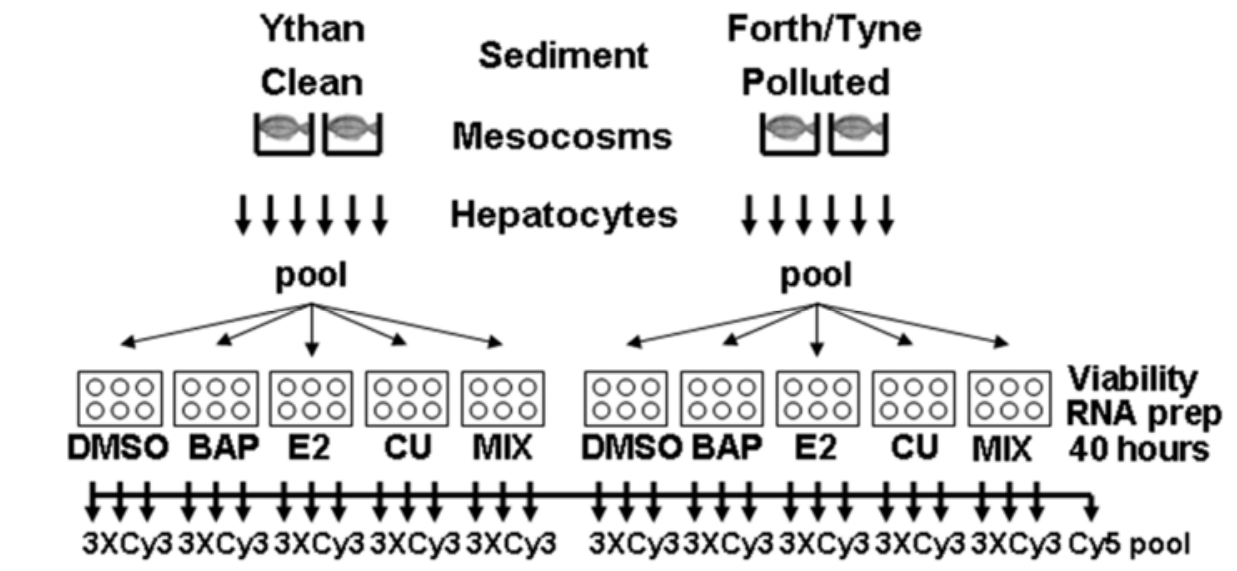

30 microarray slides, Cy3 sample versus Cy5 pool

2 way ANOVA, Sediment vs All treatments, $p<0.05$, FDR correction

Sediment GenesTreatment Genes Interacting Genes

$\downarrow \quad \downarrow$

Filter1 Pairwise comparisons, $\mathrm{p}<0.05$, T-tests

$\downarrow$

Filter2 From pairwise, 2 fold change

$\downarrow$

Output List Genes changing with sediment

Output List Genes changing with BAP, E2, CU or MIX

Output List Genes changing with BAP, E2, CU, or MIX and with sediment

Figure 1. Schematic of experimental design and procedures.

Five hundred nanograms of each total RNA sample was amplified using a commercial amplification and amino-allyl labelling kit (Amino Allyl MessageAmp II aRNA Amplification kit, Ambion). Amplified RNA yield was quantified using a Nanodrop spectrophotometer and $20 \mu \mathrm{g}$ was incubated with mono reactive NHS ester Cy3 dye (GE Healthcare). Labelled, amplified RNA probe was purified according to commercial kit instructions. A pool containing equal amounts of total RNA from each sample was labelled with Cy5 dye using the same method. Yields of labelled, amplified RNAs were quantified using a Nanodrop spectrophotometer.

The construction and validation of the GENIPOL European flounder 16K cDNA microarray used here has been described in detail previously (Williams et al., 2006) (Diab et al., 2008). The array consisted of 27648 elements, which, after contig clustering, resolve into 3336 genes. The array design with accession numbers is available through EMBL ArrayExpress, accession number A-MAXD-12 (http://www.ebi.ac.uk/microarray 
as/aer/lob?name=adss\&id=1308203622). A universal pooled reference design was used to plan microarray hybridisations (Fig1). Thus, each slide received 80pmol of Cy3 labelled, amplified RNA and 80pmol of Cy5 labelled pooled reference amplified RNA. Hybridisation procedures and solutions have been described previously (Williams et al., 2006).

Table 1. Primers and gene IDs used for QPCR.

\begin{tabular}{|c|c|c|c|}
\hline Gene & Forward (5'-3') & Reverse (5'-3') & GenBank \\
\hline$\beta$-actin & GACCAACTGGGATGACATGG & GCGTACAGGGACAGCACAGC & AF 135499 \\
\hline$\alpha$-tubulin & CACAGCCTCACTTCGTTTTG & AGATGACAGGGGCATAGGTG & AJ291985 \\
\hline Ef1A & GTTGAGCGCAAGGAGGCTAA & CGAGCATACCGGGCTTAATG & EC378684 \\
\hline Cyp1A & CAACCATGATCCAGAGCTGTG & GATTATTCTTCCTCCACTGACTCT & AJ132353 \\
\hline UGT1B & CCTTCCCGCAGAGAGTCATA & AGAGAGCCCCATGACTGAGA & AM746199 \\
\hline Vitellogenin & CTGACCTTCGTGGATATTGAG & ATCTGAGCCTCGGCATTG & AJ416327 \\
\hline Metallothionein & CTTGCGAATGCTCCAAGACTG & TGGTGTCGCATGTCTTCCCT & DV565672 \\
\hline $\begin{array}{l}\text { Glutathione } \\
\text { reductase }\end{array}$ & GGCTTCTTGCGTGAATGTTGG & CGAGGTTGCTACGATAAATGCG & AJ578037 \\
\hline Hepcidin & TCACCAGCAGAGTCAAAGAACT & ATGCTCAGCAGCTGCATTGT & DV569429 \\
\hline Diablo & CCTCATTCGAGGAGGATTCG & ACTGGGCCACCTGAATGTTT & EC377887 \\
\hline Transthyretin & ACTCCGAGCTGATGATTTGG & CCAAGACCCTCCCAGTATGA & DV566569 \\
\hline Complement C9 & GCTCATGCCCTCAAACAGGT & GTTGGACATGCCTGGTGCTA & DV569533 \\
\hline $\begin{array}{c}\text { Glutathione S- } \\
\text { transferase A }\end{array}$ & TCACGCTCACCCAGAAAATG & GAAAACCGACACATCAGCCA & DV567811 \\
\hline $\begin{array}{l}\text { CuZn superoxide } \\
\text { dismutase }\end{array}$ & TGGAGACAACACAAACGGG & CATTGAGGGTGAGCATCTTG & AJ291980 \\
\hline
\end{tabular}

Following hybridisation, microarray slides were washed, dried and scanned with a Perkin Elmer ScanArray Express microarray slide scanner. Scanned images were first analysed by Bluefuse software (BlueGnome Ltd, UK) which was used to identify features, fuse replicates and quantify $\mathrm{Cy} 3$ and $\mathrm{Cy} 5$ fluorescent signals from each feature. Bluefuse data was then analysed in Genespring GX7.3.1. (Agilent). To normalise data, all features with less than 0.01 fluorescence units were first discarded, then a Lowess per spot, per chip normalisation was carried out. Features whose sequence data formed contigs (Williams et al., 2006) were treated as on-chip replicates in Genespring.

The entire data set was first analysed by 2 Way ANOVA, implemented in Genespring, using Sediment ('clean' and 'polluted') and Treatment (BAP, EST, CU and MIX) as factors. This provided a list of features whose expression was significantly (with Bonferroni and Hochberg False Discovery Rate correction, FDR $\mathrm{p}<0.05$ ) dependent on sediment, on treatment, or which exhibited interaction between sediment and treatment. To identify features which were changed by individual treatments or which showed interaction with individual treatment and sediment, the 2 way ANOVA output list were filtered first by pairwise t-tests $(\mathrm{p}<0.05)$ and second by 2 fold up- or down-expression.

The probability that a particular biological process GO term was enriched in an output GO list (all GO annotations associated with the experimentally altered gene list) compared to the input GO list (All GO annotations associated with the array) was calculated 
using a hypergeometric distribution model as implemented by GeneSpring GX 7.3.1. The GO annotation of the flounder microarray has been described (Williams et al., 2006).

MIAME-compliant microarray data (Brazma et al., 2001) were submitted to ArrayExpress at EMBL-EBI (http://www.ebi.ac.uk/microarray-as/ae/) using MaxdLoad2 software (Hancock et al., 2005) and have been assigned accession number E-MAXD-55.

\subsection{Quantitative real time PCR (QPCR)}

QPCR was performed using the treated hepatocyte RNA extracts, or using RNA from the individual hepatocyte source fish. Complementary DNA (cDNA) was synthesized from total RNA using a commercially available kit according the manufacturers instructions (Reverse-iT Max 1st strand synthesis kit, ABgene). Briefly each reaction of $20 \mu \mathrm{L}$ contained $1.0 \mu \mathrm{g}$ of total RNA, 300ng of random hexamers and 125ng of anchored oligo-dT. Following cDNA synthesis at $42^{\circ} \mathrm{C}$ for 1 hour reactions were stopped by heating at $75^{\circ} \mathrm{C}$ for $10 \mathrm{~min}$ and cDNA diluted to $500 \mu \mathrm{L}$ total volume with water. QPCR was performed using a Quantica machine (Techne). QPCR analysis for each gene was performed in triplicate in a total volume of $20 \mu \mathrm{L}$ containing $5 \mu \mathrm{L}$ cDNA (equivalent to 10ng of input RNA), 100nM of each primer and $10 \mu \mathrm{L}$ of Absolute QPCR SYBR Green Mix 2X (ABgene). For each of target genes, forward and reverse primers were chosen from the available EST sequences by using Primer-BLAST (http://www.ncbi.nlm.nih.gov/tools/primer-blast/). Target genes were selected by consideration of microarray data and by BLAST comparison of flounder ESTs deposited in Genbank with sequences of mammalian and other fish genes of interest. Primer pairs and EST information are provided in Table 1. Thermal cycling was initiated with incubation at $95^{\circ} \mathrm{C}$ for $15 \mathrm{~min}$ in order to activate the DNA polymerase present in the mix. After this initial step, forty-five cycles of PCR were performed. Each PCR cycle consisted of

heating for $15 \mathrm{~s}$ at $95^{\circ} \mathrm{C}$ for denaturing, and then for $15 \mathrm{~s}$ at $60^{\circ} \mathrm{C}$ and $30 \mathrm{~s}$ at $72^{\circ} \mathrm{C}$ for annealing and extension. Cycle threshold $\left(\mathrm{C}_{\mathrm{T}}\right)$ values corresponded to the number of cycles at which the fluorescence emission monitored in real time exceeded the threshold limit.

Melting curve analysis was performed to indicate the production of a single product in these reactions. Standard curves were established for each gene by plotting $\mathrm{C}_{\mathrm{T}}$ values against the $\log 10$ of five different dilutions (in triplicate) of cDNA sample solutions. In addition a subset of randomly selected samples generated by each primer pair was analysed by agarose gel electrophoresis and sequencing to confirm the identity of amplicons. Realtime efficiency was determined for each gene from the slopes given by Quantsoft (Techne) software, applying the equation $\mathrm{E}=10^{(-1 / \mathrm{slope})}$. The calculated relative expression ratio of each gene was based on the PCR efficiency (E) and $\mathrm{C}_{\mathrm{T}}$ of sample compared with control, and expressed in comparison to the reference genes, $\beta$-actin, $\alpha$-tubulin and ef1A. These genes were not changed in any of the treatments, as observed after microarray analysis. Statistically significant differences in gene expression between the 'clean' vehicle (DMSO) treated hepatocytes or fish and all other possible treatment $\mathrm{X}$ sediment conditions were evaluated in group means by randomization tests (Pfaffl et al., 2002) using REST@ software. Five thousand random allocations were applied and differences were considered to be significant at $\mathrm{P} \leq 0.05$.

\section{Results}

\subsection{Flounder Biometry}

Forty eight fish in the 'clean' mesocosms (40\% mortality rate) and twenty-nine fish in the 'polluted' mesocosms (24\% mortality) died during the experiment. Chi-squared 
analysis indicated that mortality of fish on the "clean" sediment was higher than expected (24\%) and mortality of fish on the "polluted" sediment was lower than expected (Fisher's exact $\chi 2$ test, $\mathrm{p}=0.012$ ). There was a tank effect (Pearson $\chi 2$ test, $\mathrm{p}<0.001$ ); whilst tank 1 ('clean'; $20 \%$ mortality) and tank 4 ('polluted'; 45\%) had mortalities not significantly different to those expected (32\%), mortalities in tank 3 ('clean'; $60 \%$ mortality) were higher than expected and in tank 2 ('polluted'; $3.3 \%$ ) were lower than expected.

In the 7 months between introduction to the mesocosm and sampling, the flounder grew in length and weight, although they were in poorer condition (based on comparison of body $\mathrm{wt} / \mathrm{L}^{3}$ x 100, not shown). There were no treatment-related differences between length, weight, or condition (not shown). All were classed as unsexed when introduced, and there were no significant variations from the expected sex 50:50 ratio for either treatment after 7 months. There were no significant treatment-related differences (t-tests) in the gonadosomatic index (GSI; gonad weight / total weight x 100) of fish classed as either male or female after 7 months (not shown). There were no external signs of disease (fin rot, skin lesions or abnormal pigmentation) in fish after 7 months from either treatment.

\subsection{Sediment chemistry}

The contaminant profiles of each sediment are presented in Table 2. Several different priority chemical pollutants were measured in order to establish the extent to which the contaminated mesocosm represented a typical multiply-polluted estuarine sediment. Despite mixing filter sand with both Tyne/Forth and Ythan sediments, there was still a significant difference in grain size distribution between the final 'clean' and 'polluted' test sediments in the mesocosms. A difference in total organic carbon (TOC) content between the two sediments was also apparent and therefore results for organic and metal contaminants are presented as absolute values, and as values normalised to either TOC or grain size. Irrespective of normalisation, the 'polluted' mesocosm sediment showed significantly higher values for most contaminants than the 'clean' sediment. The exception was that the 'clean' sediment was more contaminated with "Total OCPs" than the "polluted' sediment, and that normalised concentrations of $\mathrm{Cd}$ and some PAHs (total "NOAA $\mathrm{n}=14 \mathrm{PAH}$ " were not significantly different between the two sediments. PAH ratios (not shown) indicated that the PAH contamination of both sediments was predominantly pyrolytic in origin (Webster et al., 2004).

In several cases sediment contaminant concentrations exceeded environmental quality standards. OSPAR Background Assessment Concentrations (BACs; (OSPAR, 2008)) were exceeded in both sediments for several PAHs (naphthalene, phenanthrene, anthracene, fluoranthene, pyrene, benz[a]anthracene, chrysene and benzo[a]pyrene) and five CB congeners, whilst the concentrations of two further $\mathrm{CBs}$ and the PAH benzoperylene also exceeded the BAC in the 'polluted'sediment. $\mathrm{CB}$ concentrations did not exceed OSPAR Environmental Assessment Criteria (EACs; (OSPAR, 2008)) in either sediment. Similarly, the 'clean' sediment did not exceed the NOAA Effects Range Low (ERL; (NOAA, 1999)) for any compounds; however, the 'polluted' sediment exceeded the NOAA ERLs for ¿DDTs, naphthalene, phenanthrene, $\mathrm{As}, \mathrm{Hg}, \mathrm{Ni}$, and $\mathrm{Pb}$. A single sample of sediment was taken from each tank when the fish were removed. Clean and polluted sediments were each pooled and analysed to provide a single measurement of PAH and CB in each sediment 8 months after setting up the mesocosms. There was no apparent decrease in total PAHs or total CBs; the measured levels fell within the $95 \%$ confidence intervals for the initials measurements. 
Table 2. Summarised absolute and normalised contaminant concentration data.

\begin{tabular}{|c|c|c|c|c|c|c|c|c|c|}
\hline & & \multicolumn{4}{|c|}{ ABSOLUTE } & \multicolumn{4}{|c|}{ NORMALIZED } \\
\hline & & \multicolumn{2}{|c|}{ Ythan } & \multicolumn{2}{|c|}{ Forth/Tyne } & \multicolumn{2}{|c|}{ Ythan } & \multicolumn{2}{|c|}{ Forth/Tyne } \\
\hline & & Mean & SD & Mean & SD & Mean & SD & Mean & SD \\
\hline \multirow{2}{*}{ Grain size } & $\%<20 \mu \mathrm{m}$ & 10.5 & 0.74 & 25.2 & 0.70 & \multirow{3}{*}{\multicolumn{4}{|c|}{$\begin{array}{l}\text { Metals normalised to grain size } \\
\text { Organics normalised to carbon }\end{array}$}} \\
\hline & $\%<63 \mu \mathrm{m}$ & 44.6 & 1.29 & $\underline{54.4}$ & 0.77 & & & & \\
\hline Carbon & $\% \mathrm{TOC}$ & 1.15 & 0.21 & 2.77 & 0.26 & & & & \\
\hline \multirow{3}{*}{ OCPs } & DDT \& metabolites & 1.09 & 0.19 & $\underline{1.72}$ & 0.48 & 2.39 & 0.20 & 1.57 & 0.52 \\
\hline & HCB & 0.18 & 0.003 & $\underline{1.33}$ & 0.06 & 0.40 & 0.07 & $\underline{1.21}$ & 0.16 \\
\hline & TOTAL OCPs & 2.25 & 0.19 & $\underline{4.07}$ & 0.53 & 4.97 & 0.51 & $\underline{3.71}$ & 0.73 \\
\hline \multirow{2}{*}{ CBs } & ICES 7 CBs & 1.21 & 0.24 & $\underline{4.43}$ & 0.71 & 2.67 & 0.66 & 4.06 & 1.00 \\
\hline & TOTAL CBs & 1.56 & 0.45 & 8.95 & 1.81 & 3.52 & 1.34 & 8.22 & 2.36 \\
\hline \multirow{4}{*}{ РАH } & Naphthalenes & 103 & 29 & $\underline{2080}$ & 718 & 228 & 37 & $\underline{1903}$ & 757 \\
\hline & NOAA $(n=14)$ PAH & 372 & 59 & 1527 & 531 & 792 & 143 & 1300 & 520 \\
\hline & TOTAL PAH & 1104 & 209 & $\underline{7267}$ & 2402 & 2444 & 505 & $\underline{6649}$ & 2626 \\
\hline & B[a]P-eq PAH & 59 & 9 & $\underline{174}$ & 65 & 129 & 17 & 159 & 68 \\
\hline \multirow[t]{5}{*}{ Organotins } & Tributyltin & $<6$ & - & $\underline{48.8}$ & 8.8 & $<4.5$ & - & 89.7 & 16.0 \\
\hline & Dibutyltin & $<6$ & - & 9.2 & 0.6 & $<2.9$ & - & $\overline{16.9}$ & 1.1 \\
\hline & As & 4.00 & 0.18 & $\underline{9.09}$ & 0.18 & 8.98 & 0.51 & $\underline{16.7}$ & 0.16 \\
\hline & $\mathrm{Cd}$ & $<0.24$ & & 0.201 & 0.075 & $<0.27$ & & 0.37 & 0.13 \\
\hline & $\mathrm{Cr}$ & 21.5 & 0.7 & 33.8 & 2.5 & 48.2 & 1.80 & $\underline{62.1}$ & 4.57 \\
\hline \multirow{5}{*}{$\begin{array}{c}\text { Metals } \\
\text { (mg/kg) }\end{array}$} & $\mathrm{Cu}$ & 7.50 & 0.32 & $\underline{24.1}$ & 1.5 & 16.8 & 0.81 & 44.2 & 2.20 \\
\hline & $\mathrm{Hg}$ & $<0.063$ & - & $\underline{0.310}$ & 0.024 & $<0.07$ & - & $\underline{0.57}$ & 0.05 \\
\hline & $\mathrm{Ni}$ & 14.0 & 0.5 & $\underline{21.4}$ & 0.5 & 31.4 & 1.38 & 39.4 & 0.67 \\
\hline & $\mathrm{Pb}$ & 11.7 & 0.3 & $\underline{51.4}$ & 1.5 & 26.1 & 0.87 & $\underline{94.4}$ & 3.19 \\
\hline & $\mathrm{Zn}$ & 39.8 & 1.1 & $\underline{98.1}$ & 1.2 & 89.3 & 3.36 & $\underline{180.2}$ & 1.87 \\
\hline
\end{tabular}

Data is mean and SD of five replicate subsamples for each of the two test sediments (clean, Ythan and polluted, Forth/Tyne) prior to addition to the mesocosm aquaria ( $\mu \mathrm{g} / \mathrm{kg}$ dry wt, unless indicated otherwise). Normalised to a TOC content of $2.5 \%$ (for organic contaminants) or to a sediment grain size of $100 \%<63 \mu \mathrm{m}$ (metals and organotins). "Less than" values indicate results below analytical detection limits. TOC $=$ total organic carbon; $\mathrm{OCP}=$ Organochlorine pesticides $(\mathrm{HCB}=$ hexachlorobenzene; total $=$ sum concentration of 20 different compounds, see methods section); $\mathrm{CBs}=$ chlorinated biphenyls (see methods); $\mathrm{PAH}=$ polycyclic aromatic hydrocarbons (NOAA compounds = sum of those PAH compounds for which NOAA Sediment Quality Guideline ER values are available (see Table 1); total = sum of 33 PAH compounds; B[a]P-equivalent concentration based upon the toxic equivalency factors for the "USEPA 16" (USEPA, 1993), see methods for details). Tyne/Forth concentrations are boldened and underlined where they are significantly different $(\mathrm{p}<0.05)$ from Ythan concentrations. "NOAA" = US National Oceanic and Atmospheric Administration.

\subsection{Comparison of individual fish livers with hepatocyte pools}

To determine whether the levels of gene expression in the hepatocyte pools were representative of gene expression in the populations of fish exposed to each type of sediment, the expression of selected genes which showed differences in microarray analysis were tested. Thus, quantitative rtPCR (QPCR) measurement of the expression levels of five genes which were changed in hepatocytes from fish from 'polluted' sediment compared to those from 'clean' sediment, showed that these genes were also changed in the same direction and by similar amounts when measured in each of the individual source fish from which the hepatocytes were prepared (Fig2). 


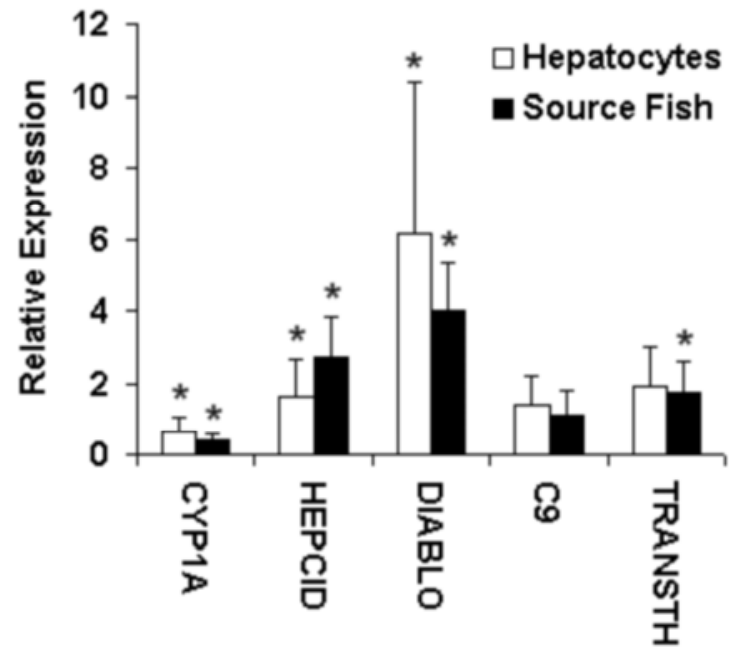

Figure 2. QPCR determination of gene expression in pooled hepatocytes and individual hepatocyte source fish.

The open bars represent the expression level of selected mRNAs in hepatocytes $(n=3$ replicate pools) from fish exposed to 'polluted' sediments relative to expression in hepatocytes $(n=3$ replicate pools) from fish exposed to 'clean' sediment. Closed bares represent the expression level of the selected mRNAs in individual flounder $(n=6)$ from 'polluted' mesocosms relative to flounder $(n=6)$ from 'clean' mesocosms. Error bars represent standard deviations of the mean and asterisks indicate a significant difference $(\mathrm{p}<0.05$, REST 2008) from the controls groups.

\subsection{Genes affected by sediment exposure or treatment}

Initially an overall exploratory analysis of all the genes affected in hepatocytes was conducted by first applying 2-way ANOVA to generate a list of significantly changed genes in any treatment or sediment group. This list was then analysed by clustering methods, to search for parameters which may be predictive of gene expression or of treatment. Thus, application of 2-way ANOVA, with false discovery rate correction (FDR $p<0.05$ ), to compare all combined treatments (DMSO, BAP, CU, E2 or MIX) with sediment ('clean' or 'polluted') returned a list genes which were significantly changed by sediment, by treatment or by both factors. Nine hundred and seventy eight of these genes were associated with sediment, 951 with treatment and 206 showed interaction between sediment and treatment. Hierarchical clustering (Fig 3) of all of these significantly altered genes based on experimental condition, showed that neither sediment origin, nor subsequent acute treatment could predict the gene expression profile. Thus, vehicle-treated hepatocytes from fish from the 'clean' sediment mesocosms clustered separately from all other groups, whilst $\mathrm{Cu}$ and E2 treated hepatocytes clustered according to sediment type rather than treatment. There was some indication that BAP and MIX treatments clustered together, irrespective of sediment type. Clustering by gene was performed hierarchically and by supervised K-means clustering for five groups. These two methods produced similar clusters (Fig 3), and examination of the $\mathrm{K}$-means clusters in more detail indicated that the majority of genes in four of the groups could be interpreted as: increased by polluted sediment (Group 2); decreased by polluted sediment (Group 3); increased by BAP or MIX (Group 1); decreased by BAP or MIX (Group 4). The fifth group did not correspond to any particular treatment, but contained the majority of genes which were present in the interaction group output from the initial 2-way ANOVA test.

Further filtering of the gene list associated with sediment was performed to generate a final output list. The filtering process first eliminated genes from the total sediment 2 way ANOVA output, which showed a $p$ value of $\leq 0.05$ after a comparison of 'clean' DMSOtreated hepatocytes with 'polluted' DMSO-treated hepatocytes. Secondly, the T-test output list was filtered to exclude genes which were less than 2 fold up or down-regulated after comparing 'clean' DMSO-treated with 'polluted' DMSO-treated. This resulted in a final output list of 57 genes whose expression was considered to be changed by exposure to polluted sediment (Table 3). The biological process GO terms associated with these genes were compared with the total GO list for the microarray, and tested for significant $(\mathrm{p} \leq 0.05)$ over-representation as implemented in GeneSpring GX 7.3.1 (Agilent). Only GO categories 
represented by more than one gene from the final gene list were considered significant and are reported in Table 4. Genes whose expression changed after each treatment (BAP, CU, E2 or MIX) were defined by the same methods. First the total 2-way ANOVA output list which was associated with treatment was filtered by T-test $p$-value using comparisons between BAP, CU, E2 and MIX treated hepatocytes, each with DMSO-treated hepatocytes. Second each of these output lists were filtered by 2-fold up or down in expression level (Supplementary Tables 1-4)
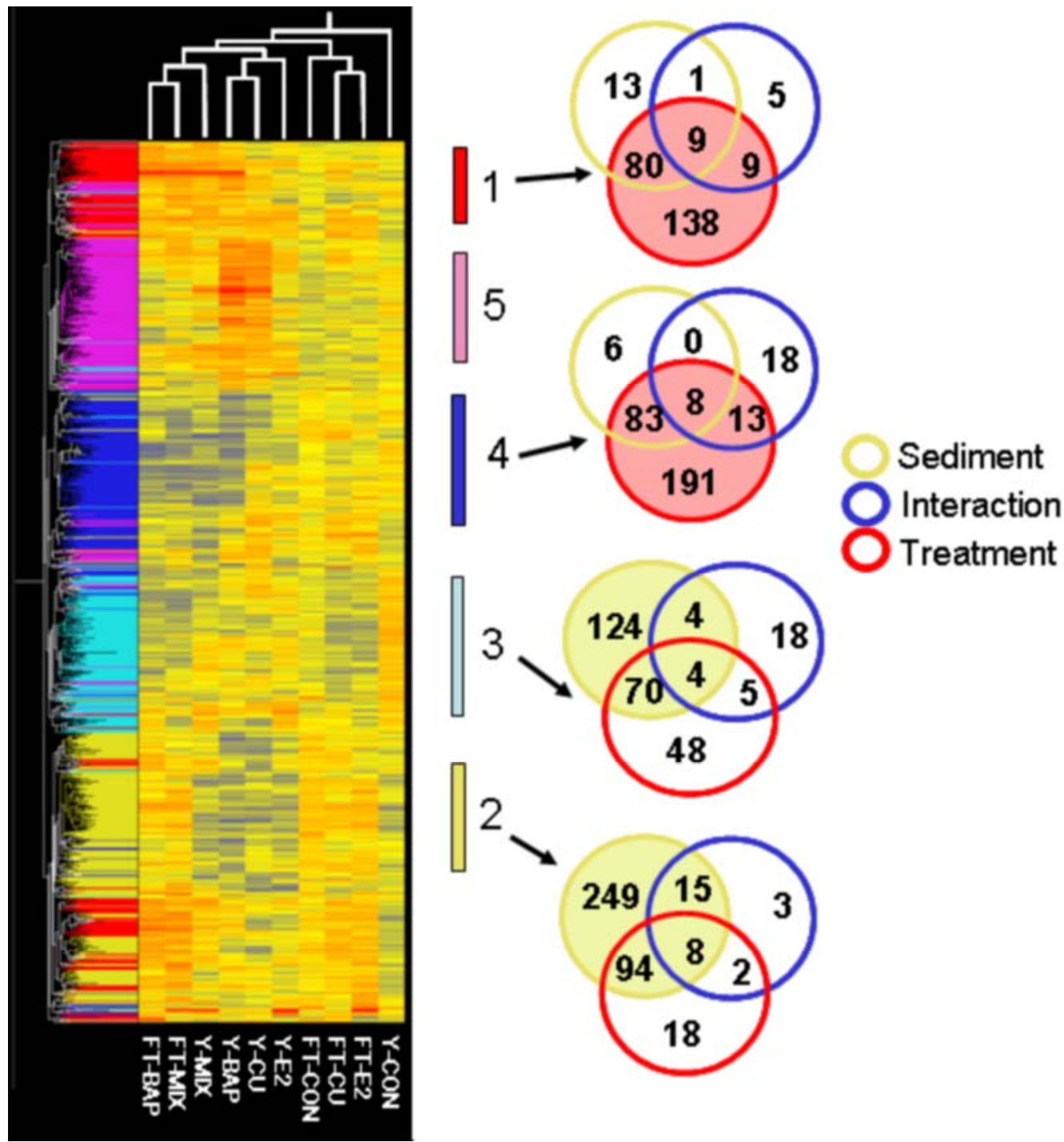

Figure 3. Clustering of 2-way ANOVA hepatocyte output list by condition and by gene.

All genes from hepatocytes which were changed according to 2-way ANOVA (Sediment X Treatment, $p<0.05$, FDR correction) were clustered heirarchically by condition (Y-CON, Ythan, untreated; Y-BAP, Ythan, benzo(a)pyrene treated; Y-E2, Ythan, estradiol treated, Y-CU, Ythan copper sulphate treated; Y-MIX, Ythan BAP+E2+Cu treated; FT-CON, Forth/Tyne, untreated; FT-BAP, Forth/Tyne, benzo(a)pyrene treated; FT-E2, Forth/Tyne, estradiol treated, FT-CU, Forth/Tyne copper sulphate treated; FT-MIX, Forth/Tyne BAP+E2+Cu treated ) and by gene (not annotated). The relative expression levels of the genes are indicated in heat map form, with red representing high and blue, low. Genes were also clustered using K-means supervised for 5 groups. Genes from the five K-means clusters are mapped onto the hierarchical gene tree using colours. The similarly coloured bars to the right of the heat map correspond to congruent clusters of genes produced by Kmeans and hierarchical methods. The numbers of genes in each cluster which belong to Sediment, Treatment or Interaction between sediment and treatment groups from 2-way ANOVA are indicated using Venn diagrams. 
Table 3. Genes whose expression changed in pooled hepatocytes from fish exposed to 'polluted' sediments compared to hepatocytes from fish exposed to 'clean' sediments.

\begin{tabular}{|c|c|c|c|c|}
\hline Clone & Fold & p-Value & Blast Hit & GenBank ID \\
\hline \multicolumn{5}{|l|}{ APOPTOSIS } \\
\hline Contig122 & 2.449 & 0.00938 & Diablo & DV566149 \\
\hline PfIL279C03 & 3.073 & 0.0141 & Diablo homolog & DV568917 \\
\hline Contig265 & 2.171 & 0.00313 & similar direct IAP binding protein with low PI & aj580508 \\
\hline PfIL227E10 & 2.563 & 0.00462 & similar direct IAP binding protein with low PI & DV566712 \\
\hline PfIL273F12 & 2.146 & 0.0434 & deoxyribonuclease II, lysosomal & EC378848 \\
\hline \multicolumn{5}{|l|}{ IMMUNE } \\
\hline Contig439 & 4.64 & $3.12 \mathrm{E}-05$ & Hepcidin precursor & DV566834 \\
\hline Contig468 & 2.409 & 0.000314 & hepcidin precursor & aj578016 \\
\hline PfIL201C01 & 2.411 & 0.0305 & hepcidin precursor & DV565788 \\
\hline PfIL201H05 & 0.48 & 0.00143 & interleukin 8 & DV565814 \\
\hline Contig59 & 2.049 & 0.00277 & interleukin 8 precursor & DV565292 \\
\hline Contig812 & 0.464 & 0.0077 & interleukin- 8 variant & DV565810 \\
\hline PfIL020F12 & 2.401 & 0.00012 & similar to small inducible cytokine B6 & DV565696 \\
\hline PfFMO2-110 & 2.891 & 0.00375 & inter-alpha-trypsin inhibitor heavy chain 2 & aj310420 \\
\hline Contig533 & 2.473 & 0.0125 & complement component $\mathrm{C} 9$ & DV565432 \\
\hline PfIL008C04 & 3.012 & 0.0392 & complement component $\mathrm{C} 9$ & DV565523 \\
\hline PfIL292H03 & 2.215 & 0.000754 & C-type lectin 2-1 (poor seq) & na \\
\hline (likely C-type lectin 2.1) & 2.082 & 0.000823 & (likely C-type lectin 2.1) & na \\
\hline PfIL 228H02 & 2.018 & 0.0157 & integrin beta 1 isoform $1 \mathrm{~A}$ precursor & DV566763 \\
\hline Contig413 & 2.176 & 0.000753 & MASP protease / haptoglobin & DV566657 \\
\hline Contig146 & 2.117 & 0.000898 & Phospholipase A2 & DV566640 \\
\hline PfIL223G08 & 2.476 & 0.00528 & similar to transthyretin (4L369) & DV566569 \\
\hline \multicolumn{5}{|l|}{ DETOXIFICATION } \\
\hline PfPARA-o2 & 2.272 & 0.00881 & Paraoxonase 2 & aj292086 \\
\hline PfIL210E01 & 2.548 & 0.0188 & hydroxyacid oxidase 1 & DV566184 \\
\hline \multicolumn{5}{|l|}{ AA METABOLISM } \\
\hline Contig483 & 2.157 & 0.00243 & betaine-homocysteine methyltransferase & DV567657 \\
\hline PfIL218B01 & 2.568 & 0.000927 & betaine-homocysteine methyltransferase & DV566389 \\
\hline \multicolumn{5}{|c|}{ MEMBRANE TRAFFICKING } \\
\hline PfIL001B04 & 2.125 & 0.0005 & Reticulon-1 & DV565298 \\
\hline \multicolumn{5}{|l|}{ RNA PROCESS } \\
\hline PfPARP-11 & 2.194 & 0.00999 & RNA binding motif protein 25 & aj310714 \\
\hline \multicolumn{5}{|l|}{ GROWTH } \\
\hline PfIL244E12 & 2.691 & 0.00199 & Insulin-like growth factor IA precursor (IGF-IA) & DV567425 \\
\hline \multicolumn{5}{|l|}{ PROTEOLYSIS } \\
\hline Contig685 & 0.49 & 4.03E-05 & High choriolytic enzyme 1 precursor & DV567267 \\
\hline \multicolumn{5}{|l|}{ ENERGY GENERATION } \\
\hline PfIL298D09 & 0.494 & 0.000176 & NADH dehydrogenase subunit 2 & DV569603 \\
\hline \multicolumn{5}{|l|}{ NUCLEAR TRANSPORT } \\
\hline PfIL249C07 & 0.392 & 0.0023 & nucleoporin $214 \mathrm{kDa}$ & DV567616 \\
\hline \multicolumn{5}{|l|}{ OXYGEN TRANSPORT } \\
\hline PfIL288E08 & 0.4 & 0.000476 & alpha-type globin & EC379099 \\
\hline \multicolumn{5}{|l|}{ RIBOSOME } \\
\hline PfIL214A05 & 0.407 & 0.00235 & $18 \mathrm{~S}$ ribosomal RNA & DV566284 \\
\hline PfIL230E06 & 2.107 & 0.0311 & $18 \mathrm{~S}$ ribosomal RNA (poor seq) & na \\
\hline PfIL209H10 & 2.325 & 0.00476 & 18S rRNA gene & EC377855 \\
\hline PfIL217F03 & 0.46 & 0.031 & 60 S ribosomal protein $\mathrm{L} 10 \mathrm{a}$ & EC377989 \\
\hline
\end{tabular}

Derived by determining which genes from 2-way ANOVA output list "sediment genes" were significantly changed (T-test $\mathrm{p}<0.05$ and $>2$-fold up or down as indicated in table) in vehicle-treated 'polluted' pooled hepatocytes versus vehicle-treated 'clean' pooled hepatocytes (T-test, $p<0.05$, indicated in table). Clone is contig name and GenBank ID gives a representative accession number for the contig. Blast hit is best match of contig sequence to non-redundant protein database by BLASTX (maximum e value $1.0 \mathrm{e}^{-6}$ ). 
Table 4. Over-represented biological process GO categories in pooled hepatocytes from fish exposed to 'polluted' sediments compared to hepatocytes from fish exposed to 'clean' sediments.

\begin{tabular}{lccc} 
Category & In Background & In List & p-Value \\
\hline GO:6955: immune response & 113 & 10 & $2.78 \mathrm{E}-05$ \\
GO:6959: humoral immune response & 30 & 3 & 0.0193 \\
GO:6956: complement activation & 23 & 3 & 0.00925 \\
& & & \\
GO:8219: cell death & 91 & 5 & 0.0291 \\
GO:6917: induction of apoptosis & 20 & 3 & 0.0062 \\
GO:43065: positive regulation of apoptosis & 22 & 3 & 0.00815 \\
GO:6919: caspase activation & 9 & 3 & 0.000528 \\
GO:8635: caspase activation via cytochrome c & 4 & 2 & 0.00218 \\
GO:19835: cytolysis & 12 & 2 & 0.0217 \\
& & & 0.00537 \\
GO:42221: response to chemical stimulus & 115 & 7 & 0.0037 \\
GO:9410: response to xenobiotic stimulus & 34 & 4 & 0.0037 \\
GO:6805: xenobiotic metabolism & 34 & 4 & 0.00925
\end{tabular}

'In Background', the number of genes present in the indicated GO category present on the total microarray. 'In List', the number of genes in the indicated GO category present in the output list (polluted versus clean sediment). The p-Value indicates the probability that the GO category is over-represented in the output list compared to the background list.

From these microarray output lists it is apparent that BAP and E2 have the expected inducing effects on, for example induction of CYP1A and vitellogenin mRNA respectively. These effects were confirmed by QPCR (Fig 4), along with measurements on other genes which were associated with sediment type (Diablo, transthyretin, hepcidin) and genes which are regularly reported in biomarker studies (UGT1B1, CuZnSOD, glutathone reductase, GSTA) Together these measurements demonstrate that 'clean' and 'polluted' hepatocytes respond similarly, although not identically when treated with the BAP or E2 or Cu. Thus, although BAP treatment caused large increases in both CYP1A and UGT1B, both previously shown to be responsive to BAP in flounder (Leaver et al., 2007), it is apparent that BAP and $\mathrm{Cu}$ also increased vitellogenin mRNA levels in 'clean' hepatocyes, but not in 'polluted' hepatocytes. Co-administration of BAP, E2 and $\mathrm{Cu}$ caused a similar level of increase in CYP1A and UGT1B as BAP alone, but levels of vitellogenin mRNA were much reduced in comparison to levels seen with E2 alone. Also apparent is that both UGT1B1, glutathione reductase and glutathione S-transeferase show a very similar treatment-response profile to that of CYP1A. Furthermore the responses of Diablo and transthyretin, which were associated with sediment treatment in microarray analysis are also associated with sediment in QPCR profile, being higher in all polluted sediment hepatocytes than in clean, irrespective of subsequent acute treatment.

\section{Discussion}

The experiment described here was designed to discover how flounder are affected after relatively long-term association with multiply polluted estuarine sediments. This was achieved by categorising genes in flounder whose expression was changed in response to chronic exposure for 7 months to contaminated sediment. In order to reduce the variability which may be associated with site-specific parameters such as salinity, temperature, or feeding behaviour, or to avoid effects of genetic differences between flounder populations, 
the experiment was conducted in mesocosms using a single population of flounders taken from a "clean" site, the Ythan estuary. These fish were then exposed to a sediment derived from their native Ythan estuary, or a mixture of sediments taken from two contaminated sites in the UK, the Tyne and Forth estuaries. After 7 months of exposure there were no differences in sex ratios or condition indexes between fish from the 'clean' and 'polluted' tanks. There was evidence of a tank-related difference in mortality rate. One of the 'clean replicate mesocosms had an unusually high mortality rate and one of the "polluted mesocosms, an unusually low rate. Such variability in survival in mesocosms, either for flounder, (Vethaak et al., 1996) or more generally for many organisms has been observed before. Whilst this variability is a problem for the assessment of effects on community structure and other higher level ecosystem variables, inter-individual variation in organisms, within or between groups is much lower (Caquet et al., 2000). Furthermore, since the higher mortality occurred in one of the clean mesocosms, it is clear that the pollutant status of the sediments is unlikely to be the cause.
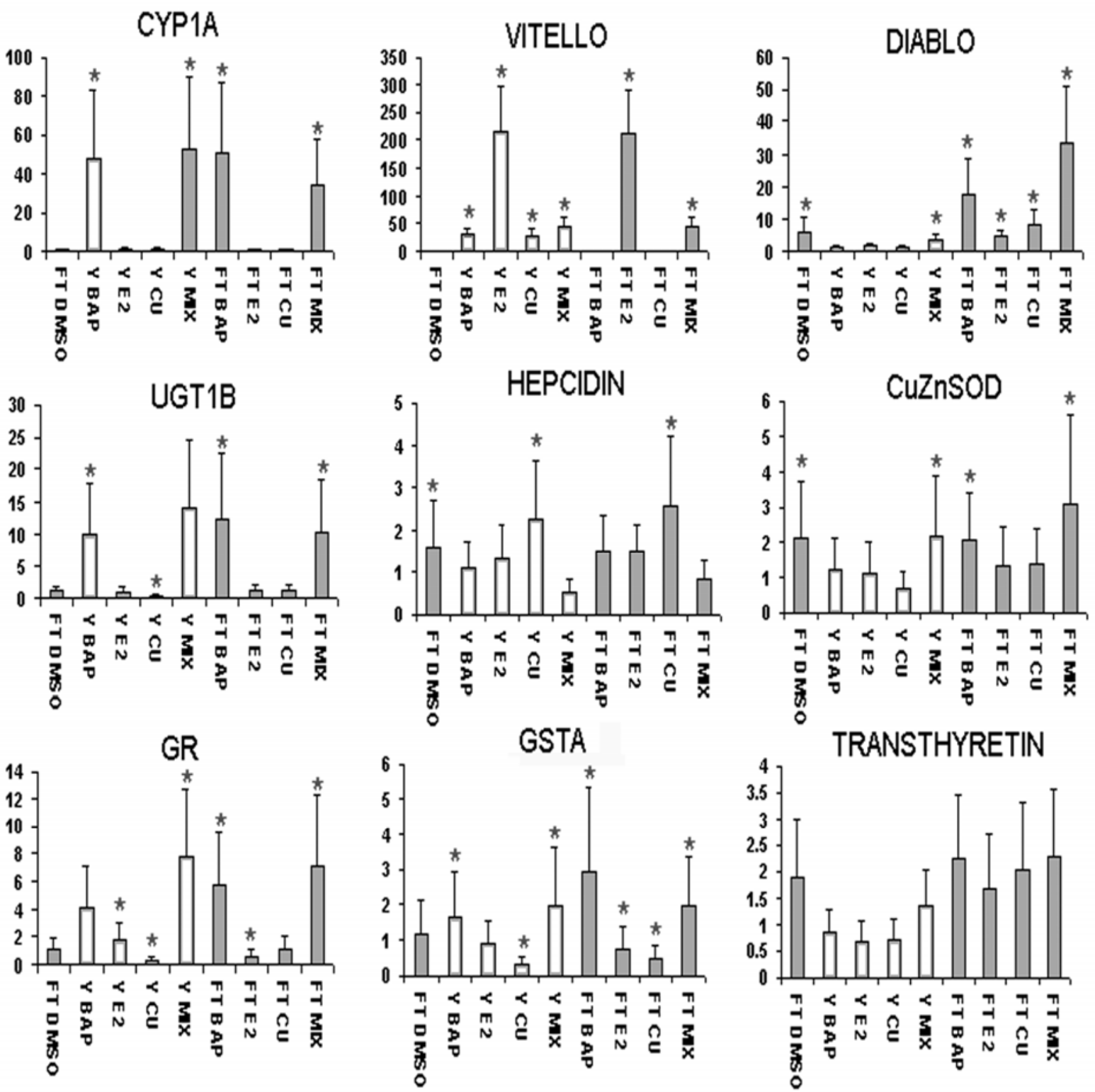

Figure 4. QPCR determination of mRNA levels for selected genes in pooled hepatocytes

Expression level in treated hepatocytes is represented relative to expression in pooled hepatocytes from fish exposed to 'clean' (Ythan) sediment. Error bars represent lower bound standard deviations of the mean and 
asterisks indicate a significant difference $(\mathrm{p}<0.05$, REST 2008) from the 'clean' group. Genes measured are CYP1A, cytochrome P4501A;, UGT1B, UGT-glucuronosyltarnsferase 1B; GR, glutathione reductase; GSTA, glutathione S-transferase A; Vitello, vitellogenin; CuZnSOD, coper-zinc-superoxide dismutase. Treatments are: Y-BAP, Ythan, benzo(a)pyrene treated; Y-E2, Ythan, estradiol treated, Y-CU, Ythan copper sulphate treated; Y-MIX, Ythan BAP+E2+Cu treated; FT-CON, Forth/Tyne, untreated; FT-BAP, Forth/Tyne, benzo(a)pyrene treated; FT-E2, Forth/Tyne, estradiol treated, FT-CU, Forth/Tyne copper sulphate treated; FT-MIX, Forth/Tyne $\mathrm{BAP}+\mathrm{E} 2+\mathrm{Cu}$ treated. To aid clarity the open bars represent measurements made in hepatocytes for fish exposed to the clean Ythan $(\mathrm{Y})$ sediment and shaded bars to measurements made in hepatocytes from the polluted Forth/Tyne (FT) sediment.

Chemical analysis of the sediments indicated that the 'polluted' test sediment contained significantly higher levels of a range of contaminants than the 'clean' sediment and were higher than recognised background concentrations. In several cases contaminant concentrations exceeded internationally recognised environmental quality thresholds, indicating a potential to cause biological effects in exposed organisms. We interpret these results as strong evidence that the mesocosms accurately reflected the natural situation of long-term, chronic contaminant exposure that flounder would be subject to in a typical industrialized, Northern temperate estuary. Despite the clear elevation of contaminant levels in the polluted sediment, there was only limited evidence of an increase in flounder tissue contaminant levels after 7 months of exposure. Of the metals only lead showed a significant elevation in flounder muscle tissue and none of the organic contaminants showed elevations (not shown). However, there was a significant elevation in bile 3-hydroxypyrene in fish from the 'polluted' mesocosms (not shown), indicating that although PAHs were not accumulating, they were being taken up, metabolised and excreted to a greater extent than in fish maintained on the 'clean' sediment.

In order to compensate for the natural variability in gene expression amongst individual flounder we analysed the transcriptome in pooled hepatocytes derived from multiple fish exposed either to polluted or to clean sediment. In addition, hepatocytes were further treated with prototypical environmental pollutants. This provided a means to directly compare chronic and acute chemical effects in hepatocytes from fish exposed to clean or polluted sediments.

Validation of the transcriptomic results consisted of a pre- and post microarray analysis. The pre-microarray analysis consisted of QPCR measurement of a representative selection of genes in the original 6 fish from 'clean' and 6 fish from 'polluted' sediment. The purpose of this test was to determine whether the expression levels of these genes in the individuals used to make the hepatocyte pools were representative of populations of fish exposed to each type of sediment, in turn indicating the validity of the pooling process. Five genes whose mRNA levels were increased in pooled hepatocytes from fish exposed to polluted sediments were selected. If these genes were also statistically significantly elevated in the individuals from which the pooled hepatocytes were derived, then the pooling procedure is experimentally valid. The results of this analysis demonstrated good agreement between the pooled hepatocytes and the individual source fish. There were no 'outliers' in the individual source fish and it was possible to show statistical significance of differences in gene expression, similar to hepatocyte replicates. We thus conclude that the gene expression measured in pooled hepatocytes was a reasonable representation of the hepatic gene expression population means of the fish in the mesocosms.

After clustering all changed genes and conditions by unsupervised hierarchical method or by a supervised clustering method, it was apparent that sediment of origin had a large effect on gene expression, irrespective of subsequent acute treatment. Treatment with $\mathrm{Cu}$ or E2 had little effect on overall gene expression compared to sediment of origin. In contrast, treatment of hepatocytes with BAP or MIX did have large effects. This overview of gene expression indicates that exposure to the multiply-polluted sediment caused clear 
changes in gene expression, and that the effects of acute exposures to single chemicals were in some cases small in comparison ( $\mathrm{Cu}$ and E2), and in other cases clearly different (BAP and MIX), showing one reason why it has been difficult to associate acute laboratoryderived transcriptomic profiles with field-derived profiles.

To derive more biological meaning from global profiles, the list of genes changed by sediment after 2 Way ANOVA was categorized by filtering using pairwise T-tests and fold expression in 'polluted' versus 'clean' sediment hepatocytes. Several over-represented gene ontology categories could be derived from this list. These included; immune response, particularly complement activation; apoptotic induction and caspase activation and xenobiotic metabolism. Consideration of the individual genes making up these GO categories, along with other genes on the output list which were not annotated, indicates that a large proportion of the contribution to the immune response and a number of other genes could also be classified as acute phase reactants (Heinrich et al., 1990). Although it is not possible to predict the effect of these liver gene expression changes on blood protein levels, the level of increase ( 2 to 3 fold) of acute phase reactant mRNA expression is indicative of low grade inflammation, typically caused by low level chronic infection, metabolic dysfunction, or chemical exposure (Forrester and Bick-Forrester, 2005) (Mullenix et al., 2005) (Yudkin et al., 2000). It is also notable that this list of genes changed by exposure to polluted sediment does not include typical biomarker genes. To further investigate, CYP1A, a gene which characteristically increases in expression following acute exposure to PAH, dioxin and planar $\mathrm{CBs}$, and is thus a very widely used exposure biomarker (van der Oost et al., 2003) was measured by QPCR in both the hepatocytes and in the individual source fish. Contrary to expectation, CYP1A mRNA was decreased in flounder exposed to 'polluted' sediments for 6 months. Many studies have reported increases in CYP1A in flounder exposed to contaminated sediments (van der Oost et al., 2003). However, other studies on the effects of chronic exposure to multiply-polluted sediments have also reported a lack of expected response by hepatic CYP1A in flounder and in other species (Eggens et al., 1996) (Reynolds et al., 2003). Notably, despite a lack of CYP1A response, flounder held long-term in mesocosms containing contaminated sediment did exhibit an increased incidence of hepatic lesions (Vethaak et al., 1996). In the experiment reported here there was no indication of any reduction in either PAH or CB levels in the sediments after 7 months. It is possible that flounder in the mesocosms simply did not accumulate sufficient contaminant to induce CYP1A, or that induction of CYP1A in specific tissues is dependent on route of exposure (VanVeld et al., 1997). Alternatively, CYP1A may become unresponsive after long-term exposure to $\mathrm{PAH}$, as has been reported in flounder fed $\mathrm{PAH}$-spiked food which demonstrated increases in CYP1A after 1 month, but no effect after 6 months of feeding (Reynolds et al., 2003).

The effects of hepatocyte treatments with prototypical pollutants were very similar to hepatic expression profiles from previous studies on acutely exposed whole flounder (Williams et al., 2008); supplementary tables 1-4). Importantly, it was clear that the expected genes, CYP1A, UGT1B for BAP and vitellogenin, choriogenin for E2 were highly elevated (Fig 4). In addition glutathione reductase and GSTA showed very similar treatment-response profiles to CYP1A, indicating that in flounder these genes are likely to be regulated by the same mechanism as CYP1A, by the aryl hydrocarbon receptor (Beischlag et al., 2008). This demonstrates that although these genes were not induced by sediment exposure at environmentally relevant concentrations, the systems which regulate them in response to contaminants were intact in the isolated hepatocytes. Some interesting interactions between sediment and treatments were also apparent, from the microarray data and also confirmed by QPCR. For example, whilst vitellogenin mRNA is highly induced by E2 in hepatocytes from both polluted and clean fish, it is also induced, albeit to a lesser extent, by BAP and by CU 
in the 'clean' hepatocytes, but not in 'polluted' hepatocytes. The reasons for this are not obvious, although both BAP and its metabolites, and more recently metals, including $\mathrm{Cu}$, have been shown to mimic estrogen when present at sufficient concentration (Darbre, 2006) (Fertuck et al., 2001). The fact that this response is clearly different depending on hepatocyte source, suggest that these effects may extend to fish living in chronically polluted and clean environments, and should perhaps be investigated further given the relevance for environmental monitoring programs.

Also apparent are effects of the mixture on hepatocytes. Although this treatment induced CYP1A, and UGT1B to the same extent as BAP alone, vitellogenin expression was much reduced compared to E2 alone. These types of interactions between pathways which depend on the aryl hydrocarbon and estrogen receptors have been previously observed in mammals (Safe and Wormke, 2003) (Beischlag and Perdew, 2005). If the same effects are seen in fish, as seems evident from the results reported here, then the results of CYP1A and vitellogenin biomarker measurements in multiply-polluted environments should be treated with caution.

In addition to biomarker genes associated with acute chemical exposure, we also measured by QPCR some of the genes which were associated with clean or polluted sediment. As indicated by global clustering of the microarray data, some of these genes (Diablo and transthyretin) showed a pattern of expression which was largely dependent on sediment of origin, rather than acute treatment. However QPCR results showed that these sediment-related genes may also be further modulated by acute exposure. An interesting example is Diablo. The expression of this gene was higher in all polluted samples than in clean, but following mixture treatment, expression in polluted hepatocytes further increases to levels 30 fold higher than in clean vehicle-treated hepatocytes. Diablo (or Smac) is a protein released from mitochondria which inhibits the activity of a repressor of caspase 3, a major apoptotic executioner (Du et al., 2000). An increase in Diablo might thus be an indication that under cell death stimuli, apoptosis is highly favoured. The signals which promote increases in Diablo are not known, but as a component of the mitochondrion it is likely associated with the intrinsic apoptotic pathway, responding to cellular damage (Shiozaki and Shi, 2004), and Diablo mimetics have recently been shown to increase the susceptibility of diseased cells to apoptosis-inducing drugs (Fulda et al., 2002) (Bank et al., 2008). The pattern and magnitude of expression changes in flounder liver indicate that Diablo, and the pathways to which it belongs are worthy of further investigation, with the prospect of developing more relevant environmental biomarkers.

\section{Conclusions}

In summary and conclusion we have shown that long-term, chronic exposure of flounder to multiply-polluted estuarine sediments causes increases in the hepatic expression of genes involved in innate immunity, inflammation and apoptotic pathways. Genes commonly employed as environmental contaminant exposure biomarkers (eg CYP1A, vitellogenin, metallothionein) were not affected, or were changed contrary to expectation in this experimental system, suggesting that they may be most useful in monitoring acute spill, or point-source contaminant inputs to the environment. The results of this experiment show that, during long-term exposure to diffuse, multiple contaminants there may be other, more useful biomarkers of exposure (or effect) which indicate changes in chronic inflammatory and apoptotic pathways.

\section{Acknowledgements}


This work was funded by the UK NERC Post-genomic and Proteomic programme grants NE/C507688/1, NE/C50766/1 and NE/C50767x/1 and also by a short term fellowship to EB from the Co-operative Research Programme of the OECD (Organisation for Economic Cooperation and Development).

\section{Appendix A}

Supplementary data detailing the genes whose expression is changed in hepatocytes from flounder exposed to clean or polluted sediments are included in Supplementary Tables 1 to 4.

\section{References}

Baker,M.E., Ruggeri,B., Sprague,L.J., Eckhardt-Ludka,C., Lapira,J., Wick,I., Soverchia,L., Ubaldi,M., Polzonetti-Magni,A.M., Vidal-Dorsch,D., Bay,S., Gully,J.R., Reyes,J.A., Kelley,K.M., Schlenk,D., Breen,E.C., Sasik,R. and Hardiman,G., 2009. Analysis of Endocrine Disruption in Southern California Coastal Fish Using an Aquatic Multispecies Microarray. Environmental Health Perspectives. 117, 223-230.

Bank,A., Wang,P., Du,C., Yu,J. and Zhang,L., 2008. SMAC mimetics sensitize nonsteroidal anti-inflammatory drug-induced apoptosis by promoting caspase-3-mediated cytochrome c release. Cancer Research. 68, 276-284.

Beischlag,T.V., Morales,J.L., Hollingshead,B.D. and Perdew,G.H., 2008. The aryl hydrocarbon receptor complex and the control of gene expression. Critical Reviews in Eukaryotic Gene Expression. 18, 207-250.

Beischlag,T.V. and Perdew,G.H., 2005. ER alpha-AHR-ARNT protein-protein interactions mediate estradiol-dependent transrepression of dioxin-inducible gene transcription. Journal of Biological Chemistry. 280, 21607-21611.

Brazma,A., Hingamp,P., Quackenbush,J., Sherlock,G., Spellman,P., Stoeckert,C., Aach,J., Ansorge,W., Ball,C.A., Causton,H.C., Gaasterland,T., Glenisson,P., Holstege,F.C.P., Kim,I.F., Markowitz,V., Matese,J.C., Parkinson,H., Robinson,A., Sarkans,U., Schulze-Kremer,S., Stewart,J., Taylor,R., Vilo,J. and Vingron,M., 2001. Minimum information about a microarray experiment (miame) - toward standards for microarray data. Nature Genetics. 29, 365-371.

Caquet,T., Lagadic,L. and Sheffield,S.R., 2000. Mesocosms in ecotoxicology (1): Outdoor aquatic systems. Reviews of environmental contamination and toxicology, Vol. 165: Springer-Verlag, New York, pp. 1-38.

Darbre,P.D., 2006. Metalloestrogens: an emerging class of inorganic xenoestrogens with potential to add to the oestrogenic burden of the human breast. Journal of Applied Toxicology. 26, 191-197. 
Diab,A.M., Williams,T.D., Sabine,V.S., Chipman,J.K. and George,S.G., 2008. The GENIPOL European flounder Platichthys flesus L. toxicogenomics microarray: application for investigation of the response to furunculosis vaccination. Journal of Fish Biology. 72, 2154-2169.

Du,C.Y., Fang,M., Li,Y.C., Li,L. and Wang,X.D., 2000. Smac, a mitochondrial protein that promotes cytochrome c-dependent caspase activation by eliminating IAP inhibition. Cell. 102, 33-42.

Eggens,M.L., Vethaak,A.D., Leaver,M.J., Horbach,G.J.M.J., Boon,J.P. and Seinen,W., 1996. Differences in CYP1A response between flounder (Platichthys flesus) and plaice (Pleuronectes platessa) after long-term exposure to harbour dredged spoil in a mesocosm study. Chemosphere. 32, 1357-1380.

Falciani,F., Diab,A.M., Sabine,V., Williams,T.D., Ortega,F., George,S.G. and Chipman,J.K., 2008. Hepatic transcriptomic profiles of European flounder (Platichthys flesus) from field sites and computational approaches to predict site from stress gene responses following exposure to model toxicants. Aquatic Toxicology. 90, 92-101.

Fertuck,K.C., Kumar,S., Sikka,H.C., Matthews,J.B. and Zacharewski,T.R., 2001. Interaction of PAH-related compounds with the alpha and beta isoforms of the estrogen receptor. Toxicology Letters. 121, 167-177.

Fisher,M.A. and Oleksiak,M.F., 2007. Convergence and divergence in gene expression among natural populations exposed to pollution. Bmc Genomics. 8 .

Forrester,J.S. and Bick-Forrester,J., 2005. Persistence of inflammatory cytokines cause a spectrum of chronic progressive diseases: Implications for therapy. Medical Hypotheses. 65, 227-231.

Fulda,S., Wick,W., Weller,M. and Debatin,K.M., 2002. Smac agonists sensitize for Apo2L/TRAIL- or anticancer drug-induced apoptosis and induce regression of malignant glioma in vivo. Nature Medicine. 8, 808-815.

Hancock,D., Wilson,M., Velarde,G., Morrison,N., Hayes,A., Hulme,H., Wood,A.J., Nashar,K., Kell,D.B. and Brass,A., 2005. maxdLoad2 and maxdBrowse: standardscompliant tools for microarray experimental annotation, data management and dissemination. Bmc Bioinformatics. 6.

Heinrich,P.C., Castell,J.V. and Andus,T., 1990. Interleukin-6 and the Acute Phase Response. Biochemical Journal. 265, 621-636. 
Leaver,M.J., Wright,J., Hodgson,P., Boukouvala,E. and George,S.G., 2007. Piscine UDPglucuronosyltransferase 1B. Aquatic Toxicology. 84, 356-365.

Mullenix,P.S., Andersen,C.A. and Starnes,B.W., 2005. Atherosclerosis as inflammation. Annals of Vascular Surgery. 19, 130-138.

NOAA. Sediment quality guidelines developed for the National Status and Trends Program. 12pp. 1999. US National Oceanic and Atmospheric Administration.

Ref Type: Generic

Oleksiak,M.F., 2008. Changes in gene expression due to chronic exposure to environmental pollutants. Aquatic Toxicology. 90, 161-171.

OSPAR. Strategy for a Joint Assessment and Monitoring Program (JAMP). 28pp. 2003. OSPAR Convenvention for the Protection of the Marine Environment of the North East Atlantic.

Ref Type: Generic

OSPAR. Draft agreement on CEMP assessment criteria for the QSR2010 meeting of the working group on monitoring (MON), Copenhagen (ICES): 24-28 November 2008 (Summary record MON 08/8/1-E, Add.1, Annex 5). 2008. OSPAR Convention for the Protection of the Marine Environment of the North East Atlantic.

Ref Type: Generic

Pfaffl,M.W., Horgan,G.W. and Dempfle,L., 2002. Relative expression software tool (REST (c)) for group-wise comparison and statistical analysis of relative expression results in real-time PCR. Nucleic Acids Research. 30.

Reynolds,W.J., Feist,S.W., Jones,G.J., Lyons,B.P., Sheahan,D.A. and Stentiford,G.D., 2003. Comparison of biomarker and pathological responses in flounder (Platichthys flesus L.) induced by ingested polycyclic aromatic hydrocarbon (PAH) contamination. Chemosphere. 52, 1135-1145.

Safe,S. and Wormke,M., 2003. Inhibitory aryl hydrocarbon receptor-estrogen receptor a cross-talk and mechanisms of action. Chemical Research in Toxicology. 16, 807-816.

Shiozaki,E.N. and Shi,Y.G., 2004. Caspases, IAPs and Smac/DIABLO: mechanisms from structural biology. Trends in Biochemical Sciences. 29, 486-494.

van der Oost,R., Beyer,J. and Vermeulen,N.P.E., 2003. Fish bioaccumulation and biomarkers in environmental risk assessment: a review. Environmental Toxicology and Pharmacology. 13, 57-149. 
VanVeld,P.A., Vogelbein,W.K., Cochran,M.K., Goksoyr,A. and Stegeman,J.J., 1997. Routespecific cellular expression of cytochrome P4501A (CYP1A) in fish (Fundulus heteroclitus) following exposure to aqueous and dietary benzo[a]pyrene. Toxicology and Applied Pharmacology. 142, 348-359.

Vethaak,A.D., Jol,J.G., Meijboom,A., Eggens,M.L., apRheinallt,T., Wester,P.W., vandeZande,T., Bergman,A., Dankers,N., Ariese,F., Baan,R.A., Everts,J.M., Opperhuizen,A. and Marquenie,J.M., 1996. Skin and liver diseases induced in flounder (Platichthys flesus) after long-term exposure to contaminated sediments in large-scale mesocosms. Environmental Health Perspectives. 104, 1218-1229.

Webster,L., Fryer,R.J., Megginson,C., Dalgarno,E.J., McIntosh,A.D. and Moffat,C.F., 2004. The polycyclic aromatic hydrocarbon and geochemical biomarker composition of sediments from sea lochs on the west coast of Scotland. Journal of Environmental Monitoring. 6, 219-228.

Webster,L., Russell,M., Walsham,P., Phillips,L.A., Packer,G., Hussy,I., Scurfield,J.A., Dalgarno,E.J. and Moffat,C.F., 2009. An assessment of persistent organic pollutants (POPs) in wild and rope grown blue mussels (Mytilius edulis) from Scottish coastal waters. Journal of Environmental Monitoring. 11, 1169-1184.

Williams,T.D., Diab,A., Ortega,F., Sabine,V.S., Godfrey,R.E., Falciani,F., Chipman,J.K. and George,S.G., 2008. Transcriptomic responses of European flounder (Platichthys flesus) to model toxicants. Aquatic Toxicology. 90, 83-91.

Williams,T.D., Diab,A.M., George,S.G., Godfrey,R.E., Sabine,V., Conesa,A., Minchin,S.D., Watts,P.C. and Chipman,J.K., 2006. Development of the GENIPOL European flounder (Platichthys flesus) microarray and determination of temporal transcriptional responses to cadmium at low dose. Environmental Science \& Technology. 40, 6479-6488.

Williams,T.D., Gensberg,K., Minchin,S.D. and Chipman,J.K., 2003. A DNA expression array to detect toxic stress response in European flounder (Platichthys flesus). Aquatic Toxicology. 65, 141-157.

Yudkin,J.S., Kumari,M., Humphries,S.E. and Mohamed-Ali,V., 2000. Inflammation, obesity, stress and coronary heart disease: is interleukin-6 the link? Atherosclerosis. $148,209-214$. 
Supplementary Table 1. Hepatocyte genes whose expression changed in response to benzo(a)pyrene treatment

List and associated numbers were generated by pairwise T-test of gene expression from treated 'clean' or 'polluted' hepatocytes versus untreated

'clean' hepatocytes and untreated 'polluted' hepatocytes respectively, using an input list from the total list of genes shown to change in response to treatment by 2 way ANOVA (FDR p<0.05). The fold increase in hepatocyes from fish held on 'clean' sediment is under the heading 'CleanFold' and from polluted sediment 'PollFold'. P values of each pairwise test are also indicated. Only genes which were $>2$ fold up or down, $\mathrm{p}<0.05$ in either hepatocyte group are included. Shading indicates where the response was $>2$ fold up or down, and where $p>0.05$. Genes without any associated annotation have been omitted from this list.

\begin{tabular}{|c|c|c|c|c|c|}
\hline Array Contig & CleanFold & PollFold & CleanPval & PollPval & BLAST \\
\hline Contig504 & 14.91 & 20.37 & 0.0169 & 0.0298 & CYP1A Cytochrome P450 1A \\
\hline PfIL303G04 & 6.596 & 1.057 & 0.0111 & 0.794 & ReO_6 protein \\
\hline Contig297 & 5.168 & 1.89 & 0.00655 & 0.0754 & similar to transient receptor potential cation channel \\
\hline Contig525 & 4.394 & 4.214 & 0.0313 & 0.0261 & UDP-glucuronosyltransferase (UGT1B gene) \\
\hline Contig765 & 4.17 & 0.999 & 0.00657 & 0.994 & JFMIP1b pseudogene premature mRNA for MIP1beta \\
\hline PfIL248A04 & 3.356 & 1.304 & 0.0208 & 0.162 & Vacuolar protein sorting-associated protein 45 \\
\hline PfIL232F01 & 3.265 & 1.973 & 0.00734 & 0.0298 & ATPase family, AAA domain containing 4 \\
\hline PfIL295F02 & 3.162 & 1.829 & 0.00643 & 0.0477 & GTP cyclohydrolase I feedback regulatory protein \\
\hline PfIL285F04 & 3.08 & 1.001 & 0.00657 & 0.994 & NADH dehydrogenase (ubiquinone) 1 beta subcomplex, 2, 8kDa \\
\hline PfIL259G06 & 2.897 & 1.37 & 0.00704 & 0.168 & KH-type splicing regulatory protein \\
\hline Contig27 & 2.56 & 0.989 & 0.028 & 0.99 & chemokine (C-X-C motif) ligand 12a \\
\hline Contig413 & 2.546 & 1.898 & 0.0092 & 0.0137 & MASP protease / haptoglobin \\
\hline Contig423 & 2.52 & 1.511 & 0.00643 & 0.0259 & calreticulin \\
\hline PfIL213G03 & 2.358 & 0.947 & 0.0474 & 0.892 & MGC84339 protein \\
\hline PfIL295C01 & 2.329 & 0.411 & 0.0642 & 0.0226 & hypothetical protein LOC552925 \\
\hline PfIL011C04 & 2.325 & 1.384 & 0.011 & 0.155 & splicing factor arginine/serine-rich 3 \\
\hline
\end{tabular}




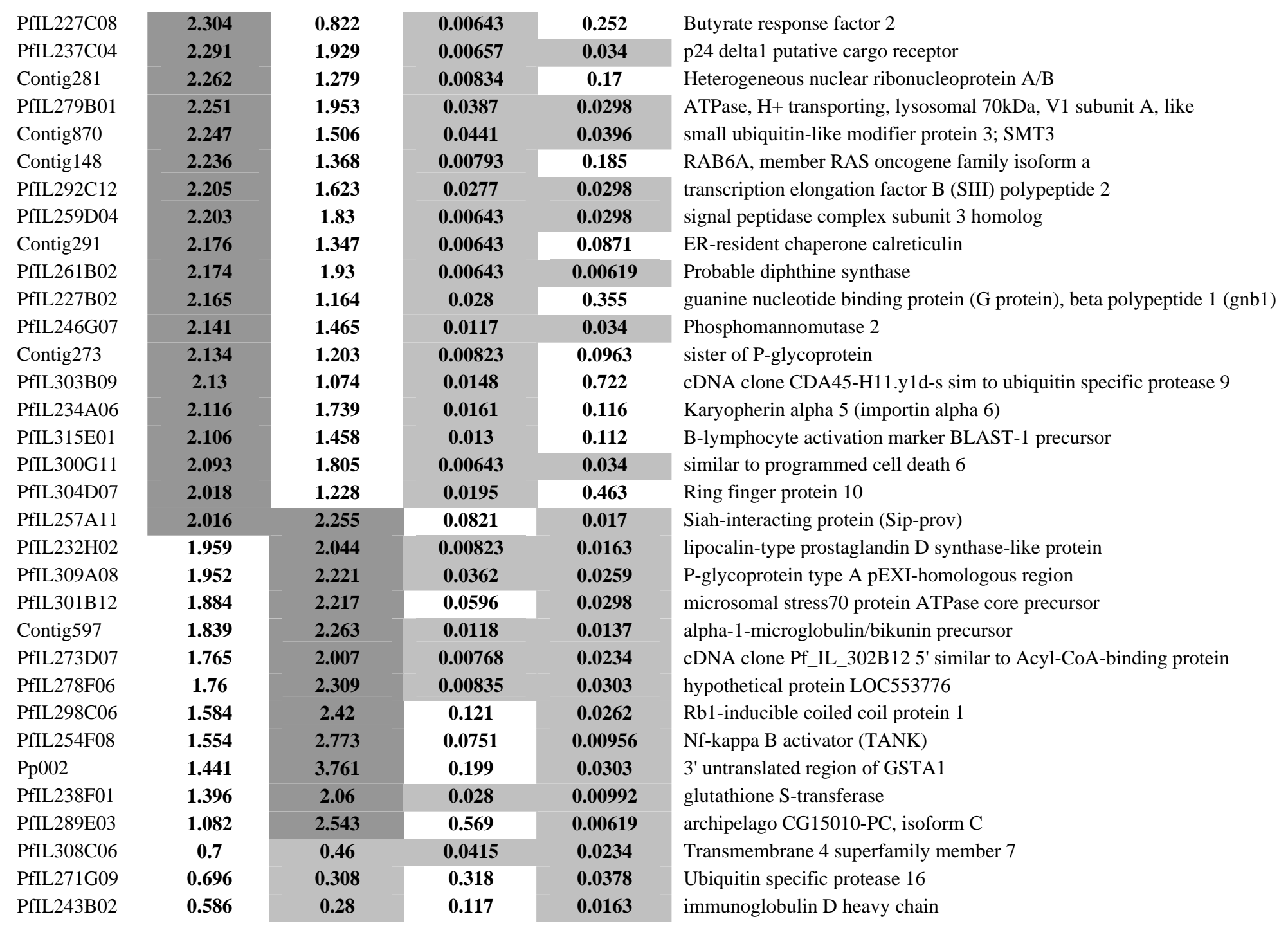




\begin{tabular}{|c|c|c|c|c|c|}
\hline Contig864 & 0.54 & 0.442 & 0.00793 & 0.0331 & Phospholipase A2 precursor \\
\hline PfIL250G09 & 0.536 & 0.476 & 0.0642 & 0.0176 & carboxypeptidase A1 (poor seq) \\
\hline Contig1106 & 0.534 & 0.486 & 0.00657 & 0.00992 & actin related protein $2 / 3$ complex subunit $5,16 \mathrm{kDa}$ \\
\hline Contig527 & 0.52 & 0.435 & 0.0116 & 0.00422 & type II keratin \\
\hline Contig633 & 0.505 & 0.477 & 0.0276 & 0.0153 & Chymotrypsin B precursor \\
\hline PfIL209E08 & 0.5 & 0.378 & 0.047 & 0.0345 & 6-pyruvoyl tetrahydrobiopterin synthase \\
\hline PfIL236A07 & 0.499 & 0.739 & 0.00734 & 0.0975 & DnaJ (Hsp40) homolog, subfamily C, member 1 \\
\hline Contig316 & 0.497 & 0.606 & 0.00657 & 0.0137 & chemotaxin \\
\hline PfIL223D11 & 0.497 & 0.621 & 0.0302 & 0.053 & eukaryotic translation initiation factor $4 \mathrm{E}$ binding protein 1 \\
\hline Contig681 & 0.495 & 0.483 & 0.0177 & 0.0298 & Elastase 1 \\
\hline PfIL276A07 & 0.493 & 0.482 & 0.0354 & 0.0348 & phosphatidate phosphohydrolase type 2a \\
\hline Contig686 & 0.491 & 0.832 & 0.0208 & 0.173 & 40S ribosomal protein S2 \\
\hline Contig914 & 0.489 & 0.492 & 0.0171 & 0.033 & trypsinogen 2 precursor \\
\hline Contig718 & 0.484 & 0.676 & 0.0161 & 0.0381 & anticoagulant protein C precursor (PROC) \\
\hline PfIL251H03 & 0.482 & 0.536 & 0.0309 & 0.0303 & unnamed protein product CAG01129 \\
\hline PfIL315H04 & 0.481 & 0.833 & 0.0121 & 0.425 & Delta3,5-delta2,4-dienoyl-CoA isomerase, mitochondrial precursor \\
\hline PfRHO-o1 & 0.48 & 0.611 & 0.0133 & 0.0298 & Rho \\
\hline PfIL298B07 & 0.474 & 0.743 & 0.0119 & 0.145 & apolipoprotein $\mathrm{H}$ precursor \\
\hline Contig1074 & 0.474 & 0.665 & 0.0157 & 0.0137 & Coronin $1 \mathrm{~A}$ \\
\hline Contig473 & 0.474 & 0.73 & 0.00704 & 0.109 & C-type lectin 1 \\
\hline Contig738 & 0.474 & 0.397 & 0.00657 & 0.0298 & High choriolytic enzyme 1 precursor \\
\hline PfIL227F02 & 0.473 & 0.492 & 0.00657 & 0.0259 & complement component 1 q subcomponent \\
\hline PfIL006C07 & 0.472 & 0.593 & 0.0239 & 0.0346 & clone sp006sk 5' similar to Coronin, actin binding protein, $1 \mathrm{~A}$ \\
\hline Contig1079 & 0.467 & 0.417 & 0.00835 & 0.0298 & trypsinogen 2 precursor \\
\hline PfIL241D10 & 0.464 & 0.62 & 0.0123 & 0.00618 & arginase, type I; A-I \\
\hline Contig648 & 0.462 & 0.459 & 0.00957 & 0.0334 & carboxypeptidase A1 \\
\hline Contig78 & 0.461 & 0.248 & 0.0389 & 0.148 & immunoglobulin light chain L2 \\
\hline PfIL298D09 & 0.46 & 0.405 & 0.00614 & 0.0137 & NADH dehydrogenase subunit 2 \\
\hline PfIL291C08 & 0.458 & 0.979 & 0.013 & 0.93 & Glutathione S-transferase, theta 3 \\
\hline PfIL273H09 & 0.454 & 0.698 & 0.00823 & 0.0629 & Hsc70-interacting protein (Hip) \\
\hline PfIL012H08 & 0.451 & 0.785 & 0.0116 & 0.551 & inhibitor of differentiation 1C; Id 6-2 \\
\hline PfIL217A03 & 0.45 & 0.743 & 0.0123 & 0.0561 & Chaperonin containing TCP1, subunit 3 (Gamma \\
\hline PfIL209A06 & 0.44 & 0.68 & 0.0156 & 0.0648 & Asparaginyl-tRNA synthetase \\
\hline
\end{tabular}




\begin{tabular}{|c|c|c|c|c|c|}
\hline Contig774 & 0.44 & 0.552 & 0.0106 & 0.02 & MHC II invariant chain \\
\hline PfIL241E06 & 0.435 & 0.471 & 0.025 & 0.151 & Golgi transport 1 homolog A \\
\hline Contig975 & 0.435 & 0.627 & 0.00614 & 0.0572 & trypsin III \\
\hline Contig629 & 0.432 & 0.583 & 0.0126 & 0.038 & prothrombin precursor \\
\hline Pp007 & 0.426 & 0.676 & 0.00657 & 0.0508 & UDP - glucose phosphatase \\
\hline Contig919 & 0.419 & 0.482 & 0.00682 & 0.034 & Chymotrypsinogen 1 \\
\hline Contig330 & 0.418 & 0.625 & 0.00823 & 0.0645 & Asparaginyl-tRNA synthetase \\
\hline PfIL209A08 & 0.412 & 0.579 & 0.0106 & 0.0298 & ATP binding protein associated with cell differentiation \\
\hline Contig986 & 0.41 & 0.441 & 0.00657 & 0.0181 & bile salt-activated lipase (BAL) \\
\hline PfIL202H02 & 0.408 & 0.588 & 0.00695 & 0.0724 & chaperonin containing TCP-1 delta \\
\hline PfSHA2F7 & 0.407 & 0.492 & 0.00614 & 0.0568 & Antifreeze glycoprotein precursor \\
\hline PfIL279B04 & 0.407 & 0.501 & 0.0116 & 0.0212 & Phospholipase A2 \\
\hline PfIL253F11 & 0.404 & 0.487 & 0.0127 & 0.00992 & NADH dehydrogenase subunit 3 \\
\hline Contig885 & 0.393 & 0.522 & 0.00614 & 0.034 & Perforin \\
\hline Contig1060 & 0.388 & 0.434 & 0.00657 & 0.0511 & trypsin \\
\hline Contig447 & 0.388 & 0.551 & 0.0149 & 0.0226 & unnamed protein product CAG03272 \\
\hline Contig346 & 0.383 & 0.571 & 0.00657 & 0.307 & unnamed protein product CAF90585 \\
\hline Contig804 & 0.382 & 0.266 & 0.00643 & 0.00619 & immunoglobulin light chain precursor \\
\hline PfIL263A03 & 0.38 & 0.692 & 0.00834 & 0.145 & poly A binding protein, cytoplasmic 1 \\
\hline PfIL243F11 & 0.379 & 0.732 & 0.0357 & 0.474 & Kruppel-like factor 2a klf2a \\
\hline Contig1049 & 0.37 & 0.485 & 0.00669 & 0.0298 & Chymotrypsinogen 2 \\
\hline PfFMO2-110 & 0.37 & 0.44 & 0.0116 & 0.0303 & inter-alpha-trypsin inhibitor heavy chain 2 \\
\hline Contig744 & 0.367 & 0.608 & 0.00657 & 0.0286 & cDNA clone CR729877 sim to fibrinogen, alpha chain isoform alpha-E \\
\hline PfILCOMA06 & 0.367 & 0.627 & 0.00643 & 0.0856 & perforin \\
\hline
\end{tabular}




$\begin{array}{lccccl}\text { PfIL307D04 } & \mathbf{0 . 3 2 6} & \mathbf{0 . 6 6 9} & \mathbf{0 . 0 1 4 6} & \mathbf{0 . 1 2 7} & \text { irn70ks / 18S rRNA (poor seq) } \\ \text { Contig998 } & \mathbf{0 . 3 2 1} & \mathbf{0 . 3 5 6} & \mathbf{0 . 0 0 6 4 3} & \mathbf{0 . 0 2 5 9} & \text { Elastase 3 } \\ \text { Contig1091 } & \mathbf{0 . 3 1 5} & \mathbf{0 . 4 2 8} & \mathbf{0 . 0 0 6 5 7} & \mathbf{0 . 0 2 9 8} & \text { elastase A precursor } \\ \text { Contig1108 } & \mathbf{0 . 3 1 2} & \mathbf{0 . 3 6 3} & \mathbf{0 . 0 1 1 9} & \mathbf{0 . 0 1 7 6} & \text { elastase 2-like protein } \\ \text { Contig903 } & \mathbf{0 . 2 9 2} & \mathbf{0 . 5 6 4} & \mathbf{0 . 0 1 1 6} & \mathbf{0 . 0 2 5 9} & \text { ribosomal RNA } \\ \text { PfIL007A06 } & \mathbf{0 . 2 8 9} & \mathbf{0 . 4 3 3} & \mathbf{0 . 0 1 0 6} & \mathbf{0 . 0 2 9 8} & \text { carboxypeptidase B } \\ \text { PfIL306D01 } & \mathbf{0 . 2 8 8} & \mathbf{0 . 9 8} & \mathbf{0 . 0 0 6 7 7} & \mathbf{0 . 9 1 4} & \text { 18S ribosomal RNA } \\ \text { PfIL214A05 } & \mathbf{0 . 2 8 5} & \mathbf{0 . 6 3 3} & \mathbf{0 . 0 0 6 4 3} & \mathbf{0 . 0 6 7 7} & \text { 18S ribosomal RNA } \\ \text { PfIL245C07 } & \mathbf{0 . 2 8 2} & \mathbf{0 . 3 2 7} & \mathbf{0 . 0 0 6 4 3} & \mathbf{0 . 0 1 0 7} & \text { Integrin alpha5 } \\ \text { PfIL259C04 } & \mathbf{0 . 2 8 1} & \mathbf{0 . 3 2 9} & \mathbf{0 . 0 0 6 1 4} & \mathbf{0 . 0 2 9 8} & \text { elastase 2 precursor } \\ \text { Contig22 } & \mathbf{0 . 2 1 6} & \mathbf{0 . 5 9 3} & \mathbf{0 . 0 0 6 4 3} & \mathbf{0 . 0 2 9 8} & \text { metallothionein } \\ \text { PfIL288C01 } & \mathbf{0 . 1 8 1} & \mathbf{0 . 1 7 8} & \mathbf{0 . 0 0 3 6 6} & \mathbf{0 . 0 1 6 4} & \text { type I keratin S8 }\end{array}$


Supplementary Table 1. Hepatocyte genes whose expression changed in response to estradiol treatment

List and associated numbers were generated by pairwise T-test of gene expression from treated 'clean' or 'polluted' hepatocytes versus untreated 'clean' hepatocytes and untreated 'polluted' hepatocytes respectively, using an input list from the total list of genes shown to change in response to treatment by 2 way ANOVA (FDR p $<0.05$ ). The fold increase in hepatocyes from fish held on 'clean' sediment is under the heading 'CleanFold' and from polluted sediment 'PollFold'. P values of each pairwise test are also indicated. Only genes which were $>2$ fold up or down, $p<0.05$ in either hepatocyte group are included. Shading indicates where the response was $>2$ fold up or down, and where $p>0.05$. Genes without any associated annotation have been omitted from this list.

\begin{tabular}{|c|c|c|c|c|c|}
\hline Array Contig & CleanFold & PollFold & CleanPval & PollPval & BLAST \\
\hline PfIL257D11 & 63.06 & 45.17 & 0.00257 & 0.0367 & Vitellogenin \\
\hline Contig458 & 50.74 & 37.97 & 0.00215 & 0.0187 & Vitellogenin \\
\hline Contig398 & 16.68 & 17.12 & 0.00257 & 3.62E-05 & choriogenin $\mathrm{L}$ \\
\hline Contig450 & 10.67 & 11.02 & 0.00215 & 0.0169 & Vitellogenin \\
\hline Contig403 & 3.987 & 3.094 & 0.0215 & 0.0169 & IgM heavy chain constant region \\
\hline PfIL304D06 & 3.035 & 2.756 & 0.0387 & 0.0338 & 6-phosphofructo-2-kinase/fructose-2,6-biphosphatase 4 \\
\hline Contig457 & 2.716 & 1.494 & 0.0178 & 0.0466 & CDA08-B12.y1d-s SHGC-CDA sim to hippocalcin-like 1 \\
\hline PfIL013A02 & 2.147 & 1.652 & 0.0163 & 0.0169 & Oligosaccharyl transferase $48 \mathrm{kDa}$ subunit \\
\hline PfIL238C10 & 2.057 & 1.736 & 0.0234 & 0.0377 & Hypothetical protein zgc:77713 \\
\hline PfIL237C04 & 2.049 & 1.788 & 0.0274 & 0.00544 & p24 delta1 putative cargo receptor \\
\hline PfIL255E12 & 2.028 & 1.548 & 0.0169 & 0.0169 & heat shock protein gp96 \\
\hline PfIL262G01 & 1.878 & 2.135 & 0.185 & 0.0338 & Trans-golgi network protein 2 \\
\hline PfIL271G09 & 0.668 & 0.32 & 0.12 & 0.0378 & Ubiquitin specific protease 16 \\
\hline Contig750 & 0.656 & 0.494 & 0.12 & 0.0378 & Tetraspan 1 \\
\hline PfIL307D04 & 0.582 & 0.472 & 0.283 & 0.0275 & irn70ks / 18S rRNA (poor seq) \\
\hline PfIL218F05 & 0.498 & 0.369 & 0.0169 & 0.0161 & P18 splicing regulatory protein \\
\hline PfIL263E08 & 0.447 & 0.63 & 0.0485 & 0.0157 & DnaJ (Hsp40) homolog, subfamily B, member 1 \\
\hline Contig903 & 0.398 & 0.47 & 0.0113 & 0.0152 & ribosomal RNA \\
\hline PfIL245C07 & 0.372 & 0.523 & 0.00685 & 0.0169 & Integrin alpha5 \\
\hline PfIL214A05 & 0.353 & 0.484 & 0.0169 & 0.0378 & $18 \mathrm{~S}$ ribosomal RNA \\
\hline Contig22 & 0.348 & 0.316 & 0.00676 & 0.00766 & metallothionein \\
\hline PfIL302H09 & 0.291 & 0.527 & 0.0115 & 0.0356 & RAP1B, member of RAS oncogene family \\
\hline
\end{tabular}


Supplementary Table 1. Hepatocyte genes whose expression changed in response to copper treatment

List and associated numbers were generated by pairwise T-test of gene expression from treated 'clean' or 'polluted' hepatocytes versus untreated 'clean' hepatocytes and untreated 'polluted' hepatocytes respectively, using an input list from the total list of genes shown to change in response to treatment by 2 way ANOVA (FDR $\mathrm{p}<0.05$ ). The fold increase in hepatocyes from fish held on 'clean' sediment is under the heading 'CleanFold' and from polluted sediment

'PollFold'. $\mathrm{P}$ values of each pairwise test are also indicated. Only genes which were $>2$ fold up or down, $\mathrm{p}<0.05$ in either hepatocyte group are included. Shading indicates where the response was $>2$ fold up or down, and where $\mathrm{p}>0.05$. Genes without any associated annotation have been omitted from this list.

\begin{tabular}{|c|c|c|c|c|c|}
\hline Array Contig & CleanFold & PollFold & CleanPval & PollPval & BLAST \\
\hline PfIL303G04 & 3.892 & 0.892 & 0.0348 & 0.276 & ReO_6 protein \\
\hline PfIL289G08 & 3.635 & 1.065 & 0.0348 & 0.703 & Myeloid/lymphoid or mixed-lineage leukemia protein 4 \\
\hline PfIL304D06 & 3.488 & 1.665 & 0.0378 & 0.215 & 6-phosphofructo-2-kinase/fructose-2,6-biphosphatase 4 \\
\hline Contig403 & 3.13 & 2.709 & 0.0349 & 0.0835 & IgM heavy chain constant region \\
\hline Contig297 & 3.057 & 1.45 & 0.0401 & 0.435 & similar to transient receptor potential cation channel \\
\hline PfIL303B09 & 2.987 & 1.638 & 0.0332 & 0.336 & cDNA clone CDA45-H11.y1d-s sim to ubiquitin specific protease 9 \\
\hline Contig870 & 2.872 & 1.686 & 0.0218 & 0.222 & small ubiquitin-like modifier protein 3; SMT3 \\
\hline PfIL213G03 & 2.794 & 2.603 & 0.025 & 0.151 & MGC84339 protein \\
\hline PfIL259G06 & 2.75 & 2.149 & 0.0428 & 0.162 & KH-type splicing regulatory protein \\
\hline PfIL295C01 & 2.725 & 0.705 & 0.0473 & 0.476 & hypothetical protein LOC552925 \\
\hline PfIL227B02 & 2.706 & 2.012 & 0.0226 & 0.117 & guanine nucleotide binding protein (G protein), beta polypeptide 1 (gnb1) \\
\hline Contig765 & 2.654 & 0.952 & 0.0401 & 0.438 & JFMIP1b pseudogene premature mRNA for MIP1beta \\
\hline PfIL229C08 & 2.607 & 1.08 & 0.0348 & 0.556 & clone uogacrs-8c7-1 \\
\hline PfIL262G01 & 2.552 & 1.387 & 0.0348 & 0.322 & Trans-golgi network protein 2 \\
\hline PfIL233G09 & 2.482 & 4.638 & 0.0332 & 0.118 & formin-binding protein 17 (rapostlin) \\
\hline PfIL303A02 & 2.356 & 3.072 & 0.0463 & 0.17 & cDNA clone 1RT138K09_A_F05 sim to taurine transporter (poor seq) \\
\hline PfIL013A02 & 2.318 & 1.696 & 0.025 & 0.0745 & Oligosaccharyl transferase $48 \mathrm{kDa}$ subunit \\
\hline PfIL227C08 & 2.313 & 1.316 & 0.00993 & 0.31 & Butyrate response factor 2 \\
\hline Contig281 & 2.263 & 1.722 & 0.0332 & 0.15 & Heterogeneous nuclear ribonucleoprotein A/B \\
\hline PfIL246G07 & 2.169 & 1.459 & 0.0417 & 0.151 & Phosphomannomutase 2 \\
\hline Contig1052 & 2.096 & 1.131 & 0.0348 & 0.636 & cDNA clone CIWU128 similar to keratin associated protein 4-12 \\
\hline PfIL292C12 & 2.079 & 1.967 & 0.0378 & 0.0669 & transcription elongation factor B (SIII) polypeptide 2 \\
\hline PfIL011C04 & 2.077 & 1.709 & 0.025 & 0.151 & splicing factor arginine/serine-rich 3 \\
\hline
\end{tabular}




$\begin{array}{lccccll}\text { PfIL243B02 } & 2.061 & \mathbf{0 . 7 3 9} & \mathbf{0 . 0 4 0 9} & \mathbf{0 . 5 4 9} & \text { immunoglobulin D heavy chain } \\ \text { PfIL001E05 } & \mathbf{1 . 9 6 2} & 2.035 & \mathbf{0 . 0 5 1 5} & \mathbf{0 . 0 0 6 7 7} & \text { RAP1A, member of RAS oncogene family } \\ \text { PfIL278D10 } & \mathbf{0 . 4 9 7} & \mathbf{0 . 4 2 2} & \mathbf{0 . 0 3 4 8} & \mathbf{0 . 1 5 9} & \text { NADH dehydrogenase (ubiquinone) Fe-S protein 4 } \\ \text { PfFMO2-ll0 } & \mathbf{0 . 4 9 1} & \mathbf{0 . 4 6 4} & \mathbf{0 . 0 3 4 8} & \mathbf{0 . 1 5 1} & \text { inter-alpha-trypsin inhibitor heavy chain 2 } \\ \text { Contig1049 } & \mathbf{0 . 4 8 4} & \mathbf{0 . 7 2 9} & \mathbf{0 . 0 3 4 8} & \mathbf{0 . 1 4} & \text { Chymotrypsinogen 2 } \\ \text { PfIL306D01 } & \mathbf{0 . 4 6} & \mathbf{0 . 5 7 5} & \mathbf{0 . 0 3 4 8} & \mathbf{0 . 1 5 7} & \text { 18S ribosomal RNA } \\ \text { PfIL265A10 } & \mathbf{0 . 4 5 4} & \mathbf{0 . 7 3 8} & \mathbf{0 . 0 4 6 3} & \mathbf{0 . 1 3 3} & \text { Hypothetical protein MGC40107 } \\ \text { Contig1060 } & \mathbf{0 . 4 5} & \mathbf{0 . 7 1 2} & \mathbf{0 . 0 3 4 8} & \mathbf{0 . 3 6 3} & \text { trypsin } \\ \text { Contig903 } & \mathbf{0 . 4 3 4} & \mathbf{0 . 5 0 6} & \mathbf{0 . 0 3 8 2} & \mathbf{0 . 1 4} & \text { ribosomal RNA } \\ \text { Contig424 } & \mathbf{0 . 4 2 6} & \mathbf{0 . 6 5 1} & \mathbf{0 . 0 3 4 8} & \mathbf{0 . 0 2 1 3} & \text { low molecular weight heat shock protein Hsp30B } \\ \text { Contig1091 } & \mathbf{0 . 4 1 7} & \mathbf{0 . 7 3} & \mathbf{0 . 0 3 4 8} & \mathbf{0 . 2 1 1} & \text { elastase A precursor } \\ \text { Contig998 } & \mathbf{0 . 4 1 5} & \mathbf{0 . 6 7 5} & \mathbf{0 . 0 4 5 3} & \mathbf{0 . 1 4} & \text { Elastase 3 } \\ \text { PfIL307D04 } & \mathbf{0 . 4 0 7} & \mathbf{0 . 6 3} & \mathbf{0 . 0 3 4 8} & \mathbf{0 . 2 6 6} & \text { irn70ks / 18S rRNA (poor seq) } \\ \text { PfIL298D09 } & \mathbf{0 . 4 0 5} & \mathbf{0 . 4 0 9} & \mathbf{0 . 0 3 4 8} & \mathbf{0 . 0 7 4 5} & \text { NADH dehydrogenase subunit 2 } \\ \text { SSH control } & & & & \\ \text { DNA } & \mathbf{0 . 3 6 1} & \mathbf{1 . 4 9 3} & \mathbf{0 . 0 3 4 7} & \mathbf{0 . 5 6 5} & \text { SSH control DNA } \\ \text { PfH70-g1 } & \mathbf{0 . 3 3 3} & \mathbf{0 . 5 8 6} & \mathbf{0 . 0 4 7 3} & \mathbf{0 . 2 4 6} & \text { heat shock protein 70 } \\ \text { PfIL313F10 } & \mathbf{0 . 2 7 3} & \mathbf{0 . 3 0 6} & \mathbf{0 . 0 3 4 9} & \mathbf{0 . 2 0 7} & \text { Rho GTPase activating protein 19 } \\ \text { PfIL218F05 } & \mathbf{0 . 2 6 8} & \mathbf{0 . 4 7 8} & \mathbf{0 . 0 2 5} & \mathbf{0 . 0 6 6 9} & \text { P18 splicing regulatory protein } \\ \text { Contig22 } & \mathbf{0 . 1 7 6} & \mathbf{0 . 4 4 8} & \mathbf{0 . 0 2 2} & \mathbf{0 . 0 7 4 5} & \text { metallothionein }\end{array}$


Supplementary Table 1. Hepatocyte genes whose expression changed in response to mixture treatment

List and associated numbers were generated by pairwise T-test of gene expression from treated 'clean' or 'polluted' hepatocytes versus untreated 'clean'

hepatocytes and untreated 'polluted' hepatocytes respectively, using an input list from the total list of genes shown to change in response to treatment by 2 way

ANOVA (FDR p <0.05). The fold increase in hepatocyes from fish held on 'clean' sediment is under the heading 'CleanFold' and from polluted sediment

'PollFold'. P values of each pairwise test are also indicated. Only genes which were $>2$ fold up or down, $\mathrm{p}<0.05$ in either hepatocyte group are included. Shading indicates where the response was $>2$ fold up or down, and where $p>0.05$. Genes without any associated annotation have been omitted from this list.

\begin{tabular}{|c|c|c|c|c|c|}
\hline Array Contig & CleanFold & PollFold & CleanPval & PollPval & BLAST \\
\hline Contig504 & 16.7 & 19.55 & 0.0174 & 0.00264 & CYP1A Cytochrome P450 1A \\
\hline Contig458 & 11.15 & 6.777 & 0.0137 & 0.121 & Vitellogenin \\
\hline PfIL257D11 & 9.263 & 6.244 & 0.006 & 0.0577 & Vitellogenin \\
\hline Contig525 & 6.841 & 4.533 & 0.0201 & 0.118 & UDP-glucuronosyltransferase (UGT1B gene) \\
\hline Contig398 & 6.476 & 6.184 & 0.0131 & 0.0155 & choriogenin $\mathrm{L}$ \\
\hline PfIL309A08 & 4.122 & 1.74 & 0.00564 & 0.0479 & P-glycoprotein type A pEXI-homologous region \\
\hline PfIL301B12 & 2.773 & 2.806 & 0.019 & 0.00607 & microsomal stress70 protein ATPase core precursor \\
\hline PfIL263A08 & 2.693 & 1.623 & 0.0222 & 0.0412 & clone cmcon186 microsatellite sequence \\
\hline PfIL257A11 & 2.659 & 2.091 & 0.00771 & 0.156 & Siah-interacting protein (Sip-prov) \\
\hline Contig413 & 2.455 & 1.771 & 0.0144 & 0.0758 & MASP protease / haptoglobin \\
\hline Contig492 & 2.442 & 2.067 & 0.00796 & 0.0155 & c-Fos \\
\hline PfIL261A12 & 2.324 & 1.234 & 0.0139 & 0.511 & Cytochrome b5 \\
\hline PfIL273D07 & 2.311 & 1.675 & 0.0186 & 0.0168 & cDNA clone Pf_IL_302B12 5' similar to Acyl-CoA-binding protein \\
\hline Contig969 & 2.238 & 1.355 & 0.0133 & 0.0199 & similar to HIG1 domain family, member 2A \\
\hline PfIL257G07 & 2.221 & 1.009 & 0.0179 & 0.876 & cDNA clone up050 similar to PTPRJ \\
\hline PfIL308C03 & 2.187 & 1.738 & 0.0119 & 0.0601 & Annexin A11b \\
\hline PfIL011H10 & 2.164 & 2.136 & 0.0137 & 0.043 & DnaJ-like subfamily A member 4 (Hsp40A4) \\
\hline PfIL237C04 & 2.156 & 2.032 & 0.00771 & 0.0457 & p24 delta1 putative cargo receptor \\
\hline PfIL278F06 & 2.151 & 2.314 & 0.00835 & 0.0178 & hypothetical protein LOC553776 \\
\hline PfIL223G08 & 2.13 & 2.495 & 0.006 & 0.0622 & similar to transthyretin (4L369) \\
\hline Contig678 & 2.116 & 1.174 & 0.006 & 0.656 & NADPH oxidase flavocytochrome b small subunit p22phox \\
\hline PfIL261B02 & 2.097 & 1.428 & 0.0274 & 0.15 & Probable diphthine synthase \\
\hline Contig405 & 2.092 & 2.181 & 0.0247 & 0.016 & cDNA clone down072 (sim to pre-acrosome localisation protein?) \\
\hline
\end{tabular}




\begin{tabular}{|c|c|c|c|c|c|}
\hline PfIL260G05 & 2.08 & 0.909 & 0.0464 & 0.417 & 14 kDa apolipoprotein \\
\hline PfIL300G11 & 2.072 & 1.632 & 0.00564 & 0.171 & similar to programmed cell death 6 \\
\hline Contig952 & 2.07 & 1.851 & 0.0202 & 0.157 & $18 \mathrm{~S}$ ribosomal RNA gene \\
\hline Contig57 & 2.04 & 1.69 & 0.0139 & 0.016 & phenylalanine hydroxylase \\
\hline Contig752 & 2.023 & 1.631 & 0.0264 & 0.0636 & Liver-expressed antimicrobial peptide $2 \mathrm{~A}$ \\
\hline PfIL259D04 & 2.012 & 1.622 & 0.011 & 0.0734 & signal peptidase complex subunit 3 homolog \\
\hline Contig459 & 2.006 & 1.909 & 0.0242 & 0.0772 & Peroxiredoxin (Thioredoxin peroxidase) (NKeF) \\
\hline PfIL285E11 & 2.004 & 1.623 & 0.0107 & 0.0182 & Transmembrane protein 4 TMEM4 \\
\hline PfIL298C06 & 1.784 & 2.103 & 0.0632 & 0.0161 & Rb1-inducible coiled coil protein 1 \\
\hline PfIL241D10 & 1.694 & 2.001 & 0.0152 & 0.00264 & arginase, type I; A-I \\
\hline PfIL254F08 & 1.518 & 2.367 & 0.203 & 0.0088 & Nf-kappa B activator (TANK) \\
\hline PfIL320H03 & 1.496 & 2.063 & 0.128 & 0.0109 & pleurocidin-like peptide WFYT (ple5, ple6), WF1L (ple7) genes, and ple10 \\
\hline Contig357 & 1.328 & 2.017 & 0.183 & 0.0088 & Cystathionine-beta-synthase \\
\hline PfH70-g1 & 1.196 & 2.725 & 0.692 & 0.0088 & heat shock protein 70 \\
\hline PfIL259A02 & 1.102 & 2.119 & 0.431 & 0.0173 & Proteasome (prosome, macropain) 26S subunit, non-ATPase, 2 \\
\hline PfIL012C12 & 0.785 & 0.411 & 0.373 & 0.00823 & S100-like calcium binding protein \\
\hline PfIL309H12 & 0.782 & 0.448 & 0.152 & 0.0276 & MHC class II alpha \\
\hline Contig801 & 0.779 & 0.399 & 0.155 & 0.0199 & Protein phosphatase 1, regulatory (inhibitor) subunit 3B \\
\hline PfIL295C01 & 0.768 & 0.492 & 0.495 & 0.00823 & hypothetical protein LOC552925 \\
\hline PfIL217D10 & 0.761 & 0.382 & 0.0573 & 0.0199 & unnamed protein product CAF91835 (EST OD-118) \\
\hline PfIL224F02 & 0.755 & 0.455 & 0.359 & 0.0179 & ZPAX \\
\hline Contig495 & 0.719 & 0.462 & 0.245 & 0.0268 & Calcium binding protein, glucose regulated protein GRP170 precursor \\
\hline Contig885 & 0.697 & 0.47 & 0.0315 & 0.0199 & Perforin \\
\hline PfIL050E09 & 0.689 & 0.465 & 0.0311 & 0.0199 & bad sequence \\
\hline Contig44 & 0.683 & 0.441 & 0.0455 & 0.00607 & chemotaxin \\
\hline Contig925 & 0.676 & 0.473 & 0.0264 & 0.00636 & unnamed protein product CAG03272 \\
\hline Contig1049 & 0.648 & 0.468 & 0.0294 & 0.0183 & Chymotrypsinogen 2 \\
\hline Contig403 & 0.617 & 0.345 & 0.0258 & 0.027 & IgM heavy chain constant region \\
\hline PfIL236A07 & 0.608 & 0.435 & 0.0215 & 0.0161 & DnaJ (Hsp40) homolog, subfamily C, member 1 \\
\hline Contig316 & 0.601 & 0.43 & 0.0392 & 0.00607 & chemotaxin \\
\hline Contig441 & 0.579 & 0.46 & 0.0208 & 0.00607 & hepcidin precursor \\
\hline Contig693 & 0.573 & 0.396 & 0.0597 & 0.0216 & selenoprotein M \\
\hline
\end{tabular}




\begin{tabular}{|c|c|c|c|c|c|}
\hline Contig447 & 0.569 & 0.46 & 0.0133 & 0.00607 & unnamed protein product CAG03272 \\
\hline Contig397 & 0.538 & 0.317 & 0.006 & 0.00264 & unnamed protein product CAG03272 \\
\hline Contig470 & 0.526 & 0.471 & 0.0281 & 0.0232 & hepcidin-like precursor \\
\hline Contig1108 & 0.51 & 0.48 & 0.006 & 0.0355 & elastase 2-like protein \\
\hline PfIL319D08 & 0.51 & 0.435 & 0.0432 & 0.0162 & kelch-like 9 \\
\hline PfIL217A03 & 0.496 & 0.709 & 0.00837 & 0.026 & Chaperonin containing TCP1, subunit 3 (Gamma \\
\hline Contig418 & 0.495 & 0.585 & 0.00564 & 0.0381 & Alpha amylase \\
\hline PfIL263G01 & 0.489 & 0.368 & 0.00837 & 0.0199 & T-lymphocyte antigen receptor beta-chain constant region 2 \\
\hline Contig1074 & 0.488 & 0.594 & 0.0292 & 0.0332 & Coronin $1 \mathrm{~A}$ \\
\hline Contig205 & 0.486 & 0.431 & 0.00564 & 0.0083 & NADPH oxidase cytosolic protein p67phox \\
\hline PfRHO-o1 & 0.486 & 0.557 & 0.0242 & 0.0176 & Rho \\
\hline PfIL007A06 & 0.485 & 0.454 & 0.0475 & 0.0199 & carboxypeptidase B \\
\hline Contig998 & 0.483 & 0.428 & 0.0142 & 0.0183 & Elastase 3 \\
\hline Contig824 & 0.48 & 0.689 & 0.0179 & 0.195 & Immunoglobulin lambda-like polypeptide 1 precursor \\
\hline PfIL226G02 & 0.479 & 0.803 & 0.0258 & 0.362 & carboxypeptidase $\mathrm{N}$, polypeptide $1,50 \mathrm{kD}$ precursor \\
\hline PfIL298D09 & 0.477 & 1.113 & 0.0102 & 0.343 & NADH dehydrogenase subunit 2 \\
\hline Contig427 & 0.476 & 0.403 & 0.00946 & 0.00607 & hepcidin-like precursor \\
\hline PfIL285A07 & 0.476 & 0.465 & 0.0292 & 0.0622 & Lysozyme c (poor seq) \\
\hline PfIL308C06 & 0.475 & 0.376 & 0.006 & 0.0126 & Transmembrane 4 superfamily member 7 \\
\hline PfIL259C04 & 0.468 & 0.442 & 0.00837 & 0.026 & elastase 2 precursor \\
\hline Contig633 & 0.467 & 0.521 & 0.00697 & 0.0819 & Chymotrypsin B precursor \\
\hline PfIL318A02 & 0.467 & 0.736 & 0.0137 & 0.0933 & Hypothetical protein zgc:73259 \\
\hline PfIL318D02 & 0.466 & 0.703 & 0.0412 & 0.223 & Elastase 1 \\
\hline PfIL260F08 & 0.466 & 0.549 & 0.0113 & 0.0381 & hypothetical protein LOC406709 \\
\hline Contig738 & 0.461 & 0.567 & 0.0139 & 0.028 & High choriolytic enzyme 1 precursor \\
\hline $\begin{array}{l}\text { PfIL223G10 } \\
\text { (likely }\end{array}$ & 0.458 & 0.622 & 0.0208 & 0.07 & Leucine-rich alpha-2-glycoprotein 1 \\
\hline lysozyme c) & 0.449 & 0.53 & 0.006 & 0.00607 & (likely lysozyme c) \\
\hline Contig181 & 0.447 & 0.516 & 0.0258 & 0.0115 & gelatinase, matrix metalloproteinase 9 \\
\hline Contig1060 & 0.445 & 0.488 & 0.00796 & 0.0573 & trypsin \\
\hline Contig1106 & 0.441 & 0.443 & 0.00835 & 0.0199 & actin related protein $2 / 3$ complex subunit $5,16 \mathrm{kDa}$ \\
\hline Contig747 & 0.44 & 0.625 & 0.0264 & 0.0355 & Myo-inositol monophosphatase \\
\hline
\end{tabular}




\begin{tabular}{|c|c|c|c|c|c|}
\hline Contig41 & 0.439 & 0.566 & 0.00771 & 0.00636 & Lysozyme c \\
\hline Contig994 & 0.429 & 0.477 & 0.0179 & 0.00888 & glyceraldehyde 3-phosphate dehydrogenase, GAPDH \\
\hline Contig527 & 0.423 & 0.419 & 0.00564 & 0.0332 & type II keratin \\
\hline PfIL211F10 & 0.419 & 0.833 & 0.006 & 0.531 & importin 9 \\
\hline Contig429 & 0.418 & 0.389 & 0.0144 & 0.00607 & hepcidin precursor \\
\hline Contig774 & 0.416 & 0.53 & 0.0208 & 0.0216 & MHC II invariant chain \\
\hline PfIL243B02 & 0.412 & 0.234 & 0.0242 & 0.0126 & immunoglobulin D heavy chain \\
\hline Contig685 & 0.408 & 0.472 & 0.0119 & 0.0276 & High choriolytic enzyme 1 precursor \\
\hline Pp005 & 0.405 & 0.512 & 0.0294 & 0.0479 & Fatty acid binding protein \\
\hline PfIL277H02 & 0.405 & 0.484 & 0.0452 & 0.028 & Ubiquitin-protein ligase RMA1 \\
\hline PfIL290E09 & 0.401 & 0.54 & 0.0311 & 0.0126 & Myeloid-associated differentiation marker \\
\hline PfIL276A07 & 0.396 & 0.481 & 0.006 & 0.0293 & phosphatidate phosphohydrolase type 2a \\
\hline PfIL202H02 & 0.394 & 0.564 & 0.0186 & 0.0879 & chaperonin containing TCP-1 delta \\
\hline PfIL251H03 & 0.369 & 0.417 & 0.0345 & 0.0176 & unnamed protein product CAG01129 \\
\hline Contig346 & 0.365 & 0.461 & 0.019 & 0.188 & unnamed protein product CAF90585 \\
\hline Contig624 & 0.35 & 0.648 & 0.0322 & 0.224 & Sulfatase modifying factor 2 precursor \\
\hline PfIL227F02 & 0.343 & 0.496 & 0.0345 & 0.0758 & complement component 1 q subcomponent \\
\hline PfIL305B08 & 0.338 & 0.896 & 0.0133 & 0.536 & GATA-binding protein 6 \\
\hline PfIL245C07 & 0.324 & 0.33 & 0.00606 & 0.0126 & Integrin alpha5 \\
\hline PfIL249C07 & 0.311 & 0.609 & 0.00564 & 0.212 & nucleoporin $214 \mathrm{kDa}$ \\
\hline PfIL313F10 & 0.301 & 0.204 & 0.0397 & 0.0844 & Rho GTPase activating protein 19 \\
\hline PfIL214A05 & 0.296 & 0.705 & 0.006 & 0.376 & 18S ribosomal RNA \\
\hline Contig804 & 0.269 & 0.212 & 0.00796 & 0.000757 & immunoglobulin light chain precursor \\
\hline PfIL288C01 & 0.131 & 0.116 & 0.006 & 0.00607 & type I keratin S8 \\
\hline
\end{tabular}

